University of Massachusetts Amherst

ScholarWorks@UMass Amherst

Masters Theses 1911 - February 2014

2010

What Went Wrong? Therapists' Reflections on Their Role in

Premature Termination

Alessandro T. Piselli

University of Massachusetts Amherst

Follow this and additional works at: https://scholarworks.umass.edu/theses

Part of the Clinical Psychology Commons

Piselli, Alessandro T., "What Went Wrong? Therapists' Reflections on Their Role in Premature Termination" (2010). Masters Theses 1911 - February 2014. 379.

Retrieved from https://scholarworks.umass.edu/theses/379

This thesis is brought to you for free and open access by ScholarWorks@UMass Amherst. It has been accepted for inclusion in Masters Theses 1911 - February 2014 by an authorized administrator of ScholarWorks@UMass Amherst. For more information, please contact scholarworks@library.umass.edu. 


\title{
WHAT WENT WRONG? \\ THERAPISTS' REFLECTIONS ON THEIR ROLE IN PREMATURE TERMINATION
}

\author{
A Thesis Presented \\ by \\ ALESSANDRO T. PISELLI \\ Submitted to the Graduate School of the \\ University of Massachusetts Amherst in partial fulfillment \\ of the requirements for the degree of \\ MASTER OF ARTS
}

February 2010

Psychology 


\section{WHAT WENT WRONG? THERAPISTS' REFLECTIONS ON THEIR ROLE IN PREMATURE TERMINATION}

A Thesis Presented

by

ALESSANDRO T. PISELLI

Approved as to style and content by:

Richard P. Halgin, Chair

Michael J. Constantino, Member

Ronnie Janoff-Bulman, Member

Melinda A. Novak, Department Chair Department of Psychology 


\section{ACKNOWLEDGMENTS}

I would like to thank my advisor, Richard P. Halgin, for his ongoing mentorship and support. I am forever grateful for his thoughtful and generous guidance. I would also like to thank the members of my committee, Michael J. Constantino and Ronnie Janoff-Bulman, for their invaluable comments and suggestions on this project.

I wish to express my appreciation to those individuals who volunteered their time and expertise by participating in this project. Special thanks to those members of the Clinical Psychology faculty who gave of their time to help me to practice and refine the interview at the heart of this project. In particular, thanks to my friend and colleague Greg MacEwan whose generosity and support elevated this project to a level of rigor and professionalism of which I am proud.

Finally, I would like to express my profound gratitude to the team of research assistants who, through their dedication and diligence, made the completion of this project possible. Kristen Boudrow, Melissa Gosian, Jillian Guskin, Stephen Grigelevich, Paul Levitan, and Garret Sacco spent countless hours coding the data, and engaging in the sometimes challenging consensual process. 


\title{
ABSTRACT \\ WHAT WENT WRONG? \\ THERAPISTS' REFLECTIONS ON THEIR ROLE IN \\ PREMATURE TERMINATION
}

FEBRUARY 2010

\begin{abstract}
ALESSANDRO T. PISELLI, B.A., UNIVERSITY OF MASSACHUSETTS AMHERST
M.A., UNIVERSITY OF MASSACHUSETTS AMHERST

Directed by: Professor Richard P. Halgin
\end{abstract}

Consensual Qualitative Research methodology was used to explore how experienced therapists understood and learned from cases of premature termination. Eleven board certified therapists participated in semi-structured interviews concerning a case of a former client who had left treatment prematurely. They offered their reflections on the client's presentation, the structure of the treatment, successful aspects of the therapy, problems in the treatment, the process of termination, and the impact on their own professional development. Core ideas were identified in each interview, and were cross-referenced to highlight the most common experiences described by the therapists. Premature terminations resulted from multiple, concurrent problems in the treatment including client un-readiness to change, therapist mistakes, and strains in the therapeutic relationship. Therapists experienced a mixture of emotions following the termination including anger, confusion, sadness, and occasional relief. Although therapists initially described premature termination as the result of client issues and psychopathology, upon 
reflection they acknowledged their own contributions to the premature termination. In the end, therapists remained uncertain about why their former clients left treatment because they lacked their clients' perspectives. Recommendations for future research and implications for clinical practice are offered. 


\section{TABLE OF CONTENTS}

Page

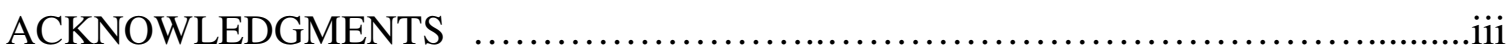

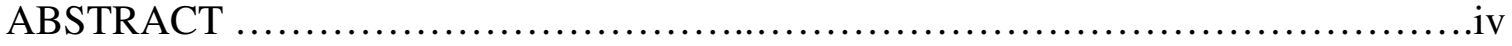

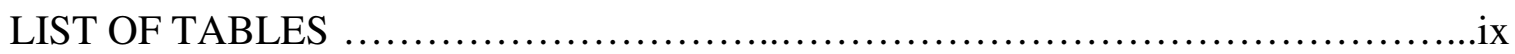

\section{CHAPTER}

I. WHAT WENT WRONG? THERAPISTS' REFLECTIONS ON THEIR ROLE IN

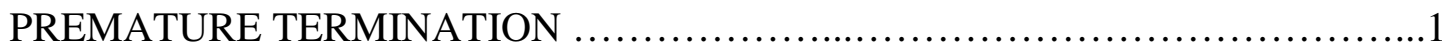

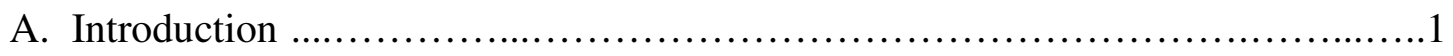

B. The Risk of Premature Termination .....................................

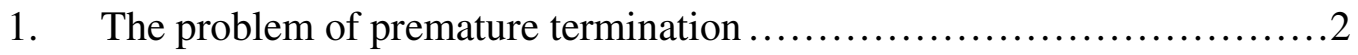

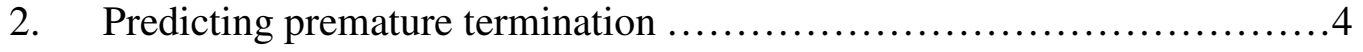

C. After the Client Is Gone ..............................................6

D. The Present Study ...............................................

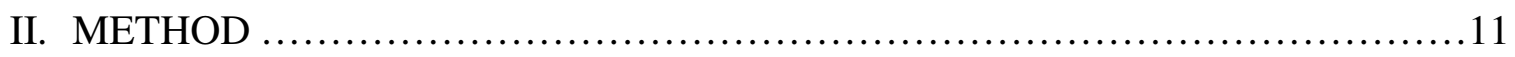

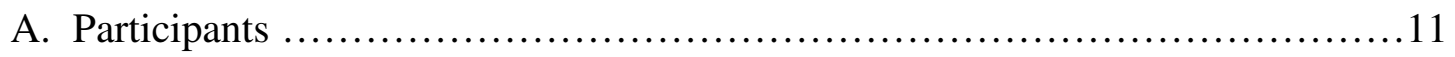

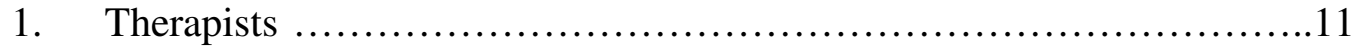

2. Research Team .................................................... 12

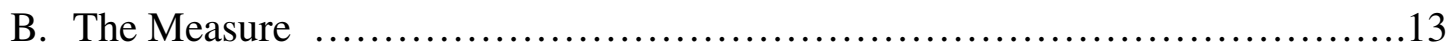

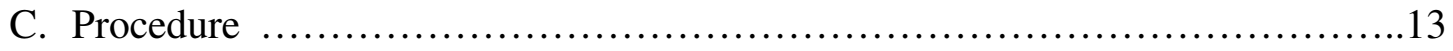

1. Recruitment of participants ....................................13

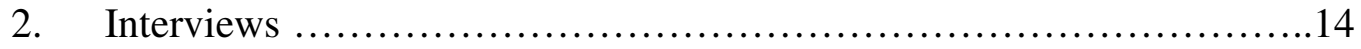

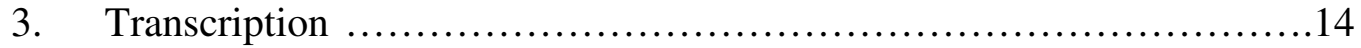

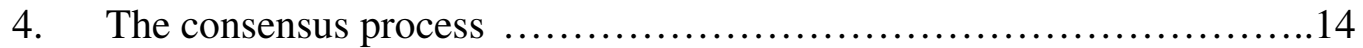

5. Coding domains and core ideas ................................... 15

6. Auditing of domains and core ideas .............................. 16 
D. Data Analysis

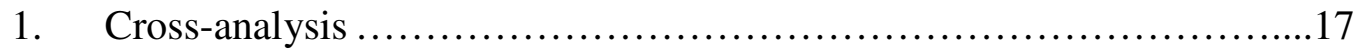

2. Auditing of cross-analysis ....................................... 17

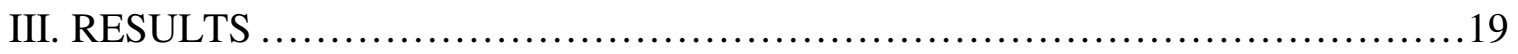

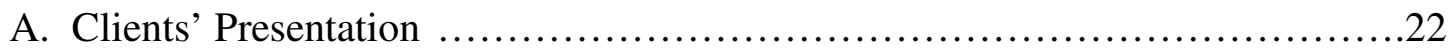

B. Duration of Treatment, and Frequency of Sessions ...........................23

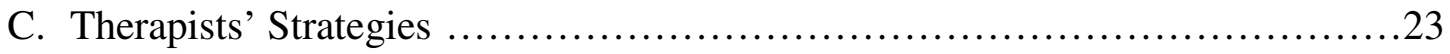

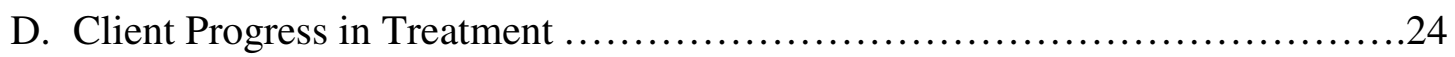

E. Client Strengths and Therapists' Positive Feelings toward the Clients ..........25

F. Client Circumstances That Interfered with Therapy ...........................27

G. Problems with Clients' Readiness of Willingness ............................27

H. Client Emotional Reactions to Therapy …..............................2 27

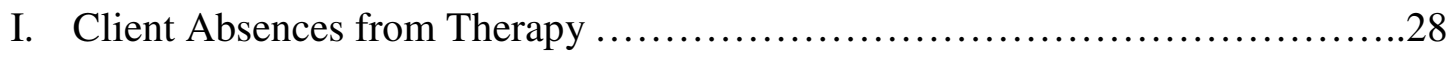

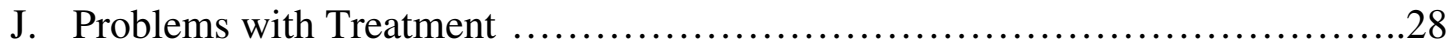

K. Mistakes Made By the Therapist .........................................28

L. Problems in the Therapeutic Relationship ..................................29

M. Therapist Emotions That Presented a Challenge …...........................29

N. Therapists' Foresight of the Termination ...................................... 31

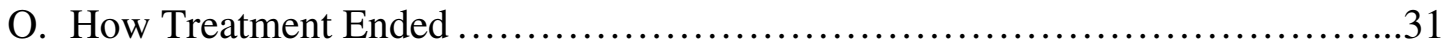

P. Events Following the Termination ..........................................

Q. Personal Impact of the Termination on the Therapist ..........................32

R. How the Therapists Made Sense of the Termination ...........................32

S. What Therapists Would Do Differently in Retrospect .........................33

T. Therapists' Remaining Questions about the Case ..............................34 
U. Lasting Effects of the Termination on the Therapist ........................ 34

V. Advice or Lessons Offered By the Therapist .............................. 35

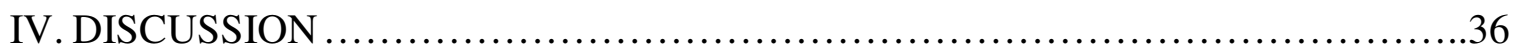

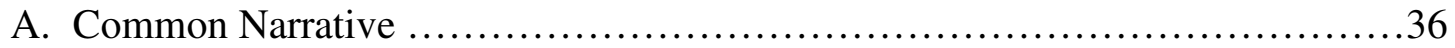

B. Clients' Presentation and the Structure of Treatment ......................... 38

C. What Went Well ...................................................... 39

D. Problems in Therapy ................................................... 40

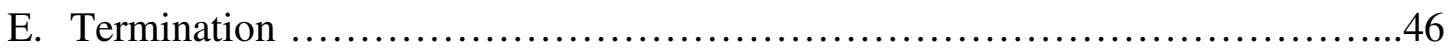

F. Professional Development ............................................48

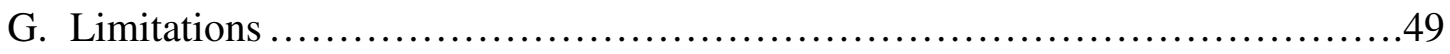

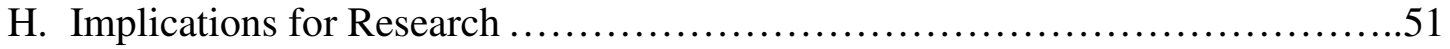

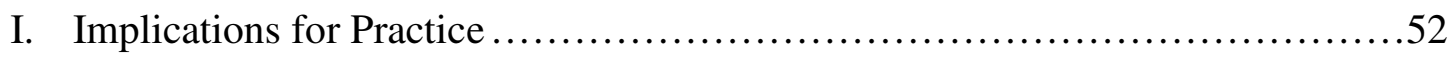

\section{APPENDICES}

A. Semi-Structured Interview ................................................. 55

B. Consent to Participate in Research .....................................57

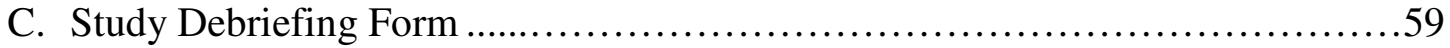

REFERENCES...........................................................6 


\section{LIST OF TABLES}

Table

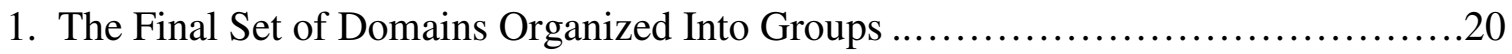

2. Domains and Categories Related to the Clients' Presentation ......................22

3. Domains and Categories Related to the Structure of Treatment ....................23

4. Domains and Categories Related to What Went Well in Therapy ...................24

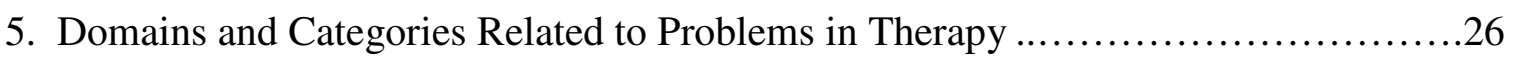

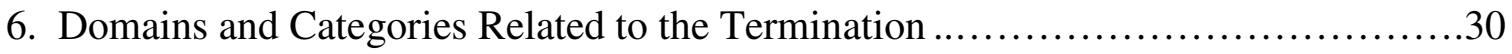

7. Domains and Categories Related to the Therapists' Professional Development .......33 


\section{CHAPTER I}

\section{WHAT WENT WRONG? \\ THERAPISTS' REFLECTIONS ON THEIR ROLE IN \\ PREMATURE TERMINATION}

\section{A. Introduction}

When clients leave in the midst of psychotherapy, their therapists may be left wondering what went wrong? Aside from terminations dictated by external circumstances such as a geographical move, a change in insurance coverage, or scheduling problems, there are instances in which clients leave treatment following problems in therapy itself. Therapists may react to these cases in a variety of ways, for example by deliberating about the extent to which their interactions with the client may have contributed to the premature termination. The proposed study will explore how psychotherapists understand and learn from problems in therapy that led one of their clients to terminate therapy prematurely. The introductory section of this paper includes: (1) a selected review of literature on premature termination; (2) a discussion of the challenges and opportunities faced by therapists after their clients have left treatment; and (3) a description of the Consensual Qualitative Research method (Hill, Thompson, Hess, Knox, Williams, \& Ladany, 2005; Hill, Thompson, and Williams, 1997), a qualitative research protocol which was be used to collect, code, and analyze the study data.

\section{B. The Risk of Premature Termination}

Premature termination is an undesirable but common outcome in psychotherapy. Research efforts to explain or predict premature termination have met with limited success due to the lack of an agreed-upon definition of the term, the variety of reasons for termination, and divergence between the perspectives of clients and therapists 
(Ogrodniczuk, Joyce \& Piper 2005; Reis \& Brown, 1999). Despite these limitations, research indicates that problems in the therapeutic alliance are associated with a heightened risk of premature termination, and researchers suggest ways that therapists can mitigate this risk.

The problem of premature termination. In their review of three decades of research, Reis and Brown (1999) found that rates of treatment dropout ranged from 30 to $60 \%$. Clients who terminate therapy prematurely do not receive the full benefit of treatment, and may experience a sense of failure (Ogrodniczuk et al., 2005). In an early discussion of the problems that follow premature termination, Pekarik (1985) pointed out that service providers incur additional costs in time and money, and therapists experience rejection and failure, and are at risk of job-dissatisfaction and burnout.

Researchers have found that synthesizing study findings is difficult due to the lack of a consistent definition of treatment dropout (Barrett et al., 2008; Corning \& Malofeeva, 2004; Reis \& Brown, 1999). Scholars have used various terms to describe a client who leaves treatment early: dropout, defector, premature terminator, unilateral terminator (Reis \& Brown, 1999) and client initiated terminator (Connell et al., 2006). Moreover, researchers have operationalized premature termination differently. Wierzbicki and Pekarik (1993) found that among 125 studies, “dropout” rates varied depending on how researchers defined the term.

Further complicating research efforts, clients who leave therapy early in treatment appear to differ from those who do so later on. Frayn (1992) conducted a prospective study of client characteristics associated with psychotherapy dropout, and found that half of the clients who terminated prematurely did so within the first month. These clients 
appeared to leave therapy due to either a lack of motivation, or an overly negative early transference. Meanwhile, clients who terminated later in therapy left for a wider range of reasons. Frayn (2008) and others (Connell, Grant, and Mullin, 2006; Derisley \& Reynolds, 2000) have since confirmed this difference between early and late-treatment terminators, and have recognized the distinct challenges of beginning and maintaining therapy.

Pekarik $(1983,1992)$ sought to understand the reasons clients have for leaving treatment early, challenging the assumption that all psychotherapy dropouts are treatment failures. He contacted former psychotherapy clients, and found that they most often cited problem improvement, environmental obstacles, and dissatisfaction with services as their reasons for terminating. On the other hand, therapists tended to perceive all dropouts as treatment failures (Pekarik, 1992).

Clients and therapists have distinct perspectives, and may offer different explanations for why a therapy has ended. Extending Pekarik's categorizations to therapists, Todd, Deane, and Bragdon (2003) found that clients and therapists agreed less often on symptom improvement than on environmental obstacles as reasons for premature termination. In their review of the literature on client attrition, Barrett and her colleagues (2008) noted that therapists are less accurate when rating their clients' reasons for leaving if those reasons are negative. Pekarik (1983) pointed out that clients might be reluctant to express negative feelings about therapy. Moreover, it is difficult for the therapist or researcher to ask clients their reasons for terminating after they have rejected services and discontinued contact (Derisley \& Reynolds, 2000; Samstag, Batchelder, Muran, Safran \& Winston, 1998; Todd et al., 2003). 
Predicting premature termination. As a result of the divergent definitions of, varying reasons for, and discrepant perspectives on premature termination, attempts to identify specific variables that predict premature termination have met with limited success. In a 1999 literature review Reis and Brown (1999) commented that demographic variables, such as client age, gender, and social stability, are inconsistent predictors of dropout. They also noted predictive inconsistency with regard to client diagnosis, symptom level, presenting problem, and experience with therapy. Furthermore, therapist factors such as gender and experience predicted premature termination in some studies, but not in others. Corning and Malofeeva (2004) reviewed the literature and concluded that "to date there has been almost no concrete identification of the factors that influence the likelihood of [premature termination]" (p. 354).

Demographic variables associated with lower socio-economic status (SES), such as ethnic minority status and fewer years of education most consistently predict premature termination (Arnow et al., 2007; Connell et al., 2006; Wierzbicki \& Pekarik, 1993). Yet, several researchers suggest that the association between lower SES and premature termination is the result of poor client-therapist matching rather than factors associated directly with poverty. Pekarik (1985) proposed that clients of lower SES may expect therapy to involve fewer sessions, more direct advice, faster improvement, and more focus on specific symptoms when compared to their therapists' expectations. Reis and Brown (1999) and Wierzbicki and Pekarik (1993) echoed the view that divergent client and therapist expectations increase the risk of unilateral termination. Maramba and Nagayama Hall (2002) summarized the research, finding a small overall effect of ethnic match on rates of dropout among ethnic minority clients. They suggested that ethnic 
match has been used as a proxy for cultural match, and that the cultural match between client and therapist is more likely to impact the risk of premature termination.

Failing to identify consistent demographic predictors of premature termination, researchers turned their attention to more subtle features of the client-therapist relationship. Reis and Brown (1999) found that client personality characteristics, such as counseling readiness and psychological mindedness, were associated with continuation in therapy, while characteristics such as defensiveness, impulsivity, low frustration tolerance, and poor motivation were associated with premature termination. Frayn (1992) found that therapists rated treatment dropouts as having ego deficits such as lower levels of introspection, frustration tolerance, impulse control, and motivation. Treatment dropouts reported more hostile feelings toward past caregivers and their present life circumstances, and their therapists reported more hostile feelings toward these clients. Hilsenroth, Handler, Toman, and Padawar (1995) compared terminators and completers on personality variables from the Minnesota Multiphasic Personality Inventory-2 (MMPI-2) and the Rorschach. They found that clients who ended therapy prematurely tended to be less disturbed, less aggressive, more cooperative, and less in need of closeness with their therapist. Mahon (2000) reviewed the literature on clients diagnosed with eating disorders and concluded that client factors associated with less secure attachment styles predicted dropout in that population.

Corning and Malofeeva (2004) reviewed previous studies on premature termination and found that research on the subject had failed to overcome methodological problems. They suggested that alternative research methods, such as survival analysis, which explore changing processes over time could be used to address shortcomings in 
research based on more conventional methods. Similarly, Maramba and Nagayama Hall (2002) suggested that outcome researchers should focus on the effects of how process variables, rather than static client or therapist traits, affect the course of treatment. To that end, Barrett and her colleagues (2008), as well as Mahon (2000), recommended the use of qualitative analysis to clarify the nature of premature termination, and to explore its precipitants during the course of therapy.

\section{After the Client Is Gone}

When a client drops out of treatment, the therapist may react in a variety of ways. The therapist may dismiss the termination as an unfortunate consequence of external circumstances, or attribute it to the psychopathology of the client. Alternately, if the termination came as a surprise, the therapist may reflect on the preceding sessions in an effort to explain the termination, or to discover hints of trouble that he or she may have missed. A therapist may also experience distressing emotions, and may question his or her abilities. How a therapist reacts to a client's premature termination will have implications for his or her professional development, and work with future clients.

Researchers have conducted little research exploring therapists' reflections on cases of premature termination. A query of the publication database PsychInfo, using search terms such as "premature termination" and "dropout" in combination with "therapist", "development", or "supervision" resulted in only a few recent dissertation abstracts on the topic. With so little previous research on the topic, we are left to speculate on the thoughts of therapists in the wake of a premature termination. Perhaps therapists identify some fault in either the client or themselves that would explain the failure of treatment. Therapists may attribute the termination to a shortcoming of their 
clients such as a lack of motivation, a reluctance to get well, maladaptive personality functioning, or an unstable attachment style. Therapists may also blame themselves for the premature termination, citing such mistakes as failing to empathize with their clients, missing an important sign of difficulty in therapy, or timing an intervention poorly.

Aspects of psychotherapy may actually predispose therapists to having difficulty in the wake of an unexpected termination. Guy and others have written lucidly about the personal challenges faced by those who work as therapists (Guy, 1987; Guy, Poelstra \& Stark, 1989; Norcross \& Guy, 1989). Guy (1987) points out that "many are drawn to a career in psychotherapy due to a hunger for closeness, intimacy, and meaningful attachment" (p. 86), adding that it is not uncommon, or necessarily undesirable, for a therapist to become attached to his or her clients.

Therapists often care deeply for their clients, and are driven by a desire to understand and alleviate their suffering. A curious byproduct of therapy is that therapists may begin to see themselves as their clients" "good therapist" or even "savior" (Guy, 1987). Some clients actively promote an image of their therapists as idealized and omnipotent healers. Therapists may be more willing to accept such an image given the difficult and only intermittently rewarding task of providing psychotherapy. It is also important to acknowledge that therapy is a paid service, and that the departure of a client may also be a financial strain on therapists. Given these predisposing factors, it is reasonable to expect that therapists would feel troubled when their clients leave treatment early.

Guy (1987) noted that therapists may feel hurt, rejected, abandoned, or betrayed by their clients, as well as disappointed with the notion that they have failed. Reis and 
Brown (1999) added that therapists may feel demoralized in the empty time created by their clients' absence. Ogrodniczuk and his colleagues (2005) point out that "for therapists whose own self-esteem is closely tied to their ability to help others, the loss of a patient through premature termination threatens their sense of self-worth", and may be experienced as a "narcissistic injury" (p. 58). Frayn $(1992,2008)$ highlighted the feelings of impotence and rage that can arise in therapists, particularly when the client and therapist were in the midst of a transference-countertransference enactment.

The powerful negative emotions that premature termination can trigger may interfere with a therapist's ability to work effectively. Guy and his colleagues (1989) found that some therapists felt that they had offered poorer quality, or even inadequate, treatment as a result of their own personal distress. Farber (1983) found patient premature termination to be the third greatest source of stress (behind client suicidal threats and hostility) among psychologists, psychiatrists, and social workers. A number of researchers have warned that the failure of treatment can erode therapists' sense of confidence and effectiveness (Connell et al., 2006; Frayn, 1992, 2008; Ogrodniczuk et al., 2005).

A therapist's reaction to a client's departure may significantly impact his or her work with future clients. According to Guy (1987), therapists may overcompensate for these painful experiences by distancing themselves from their current and future clients, or conversely by becoming overly connected with their clients. In either case, the therapist risks making the mistake of putting his or her own needs for safety or connection before those of the client. Pekarik (1985) cautioned that treatment dropouts can chip away at the job satisfaction of therapists, and may ultimately result in "burnout". 
If unchecked, the loss of interpersonal satisfaction and pleasure can also bleed into the therapist's personal life (Guy, 1987; Norcross \& Guy, 1989; Ogrodniczuk et al., 2005).

The personal consequences of premature termination create complex challenges for therapists. As Guy (1987) points out, therapists are caught in a paradox in which they work to foster both attachment and independence, closeness and separation. The constant coming and going of clients "leaves the therapist experiencing repeated feelings of loss, loneliness, abandonment, and isolation" (p. 90). Ironically, therapists who work to develop strong therapeutic alliances by offering their clients genuine warmth, empathy, and understanding consequently make themselves more vulnerable to the consequences of treatment failure.

Given the commonality of premature termination, "surprisingly, very little has been written about the effects of patient-initiated premature termination on therapists" (Ogrodniczuk et al., 2005, p. 58). In the wake of a failed treatment, a therapist may look back on his or her work in search of explanations. In the absence of the departed client's perspective, the therapist may find some indication of what went wrong by reflecting on his or her therapeutic alliance with the client. In the absence of relevant research, scholars stand to benefit from an exploration of how therapists contribute and respond to cases of premature termination.

\section{The Present Study}

The present study focused on the reflections of experienced psychotherapists on cases of premature termination. More specifically, this study explored the ways in which experienced therapists understand and have learned from such cases. The study asked the following questions: 
1. How and when do therapists observe warning signs of premature termination?

2. How do therapists understand the causes of premature termination, and what are their views regarding their own role in the outcome in these cases?

3. What efforts do therapists who have experienced premature terminations wish they had made to avert the termination?

4. What lasting personal impact do therapists experience as a result of premature terminations? In other words, how have 'failed' cases influenced their self-views regarding therapeutic competency, attunement, and capacity to relate to clients?

5. What lasting professional impact do therapists experience as a result of premature terminations? In other words, how have 'failed' cases influenced their efforts to avert premature termination with subsequent clients? 


\section{CHAPTER II}

\section{METHOD}

The research design for this study was based on the Consensual Qualitative Research (CQR) methodology outlined by Hill, Thompson, and Williams (1997) and later revised by Hill and her colleagues (2005). The CQR method relies on interview data gathered from those who have had first-hand experience with the phenomena in question. Using CQR, this study will produce results that closely reflect the participating therapists' reports, permitting similarities and differences in their experiences to emerge. Also, CQR allows participants to report on their internal experiences, allowing this study to explore therapists' personal experiences with premature termination. The CQR method requires a team of researchers to reach consensus when coding interview data, thereby mitigating the influence of researcher biases and expectations. Finally, CQR offers a systematic way of identifying common meaning among interview data, and assessing how well results represent the sample of participants. This approach is replicable, and therefore falsifiable, and produces findings that are both methodologically rigorous, and clinically applicable.

\section{A. Participants}

Therapists. Eleven practicing psychotherapists were asked to discuss a former client who terminated therapy prematurely due to problems in the therapeutic alliance. Participants were recruited through the public database of the American Board of Professional Psychologists (ABPP), an organization comprised of experienced psychotherapists. In order to participate in this study, psychotherapists must have identified their approach to treatment as integrative or eclectic. Also, participating 
therapists were asked to describe a case which involved a client that had not been diagnosed with an Axis I psychotic or substance abuse disorder. Finally, the therapists were asked to describe a termination that: (1) was premature in that the therapy ended before significant therapeutic progress had been achieved, (2) occurred after at least four therapy sessions (ensuring that the cause was not lack of client motivation or poor clienttherapist match, and (3) was not due to a geographical move or a change in the client's ability to pay for therapy.

Research team. The research team was comprised of six primary members, one auditor, and one research mentor. The six primary team members included the principal investigator, and five advanced undergraduates who were also Research Assistants in their Department of Psychology at the University of Massachusetts or Amherst College. RAs were selected based on their understanding of psychotherapeutic phenomena, their maturity, their ability to work well both independently and on a team, and their comfort in sharing their viewpoints and engaging in intense dialogue about the topics under investigation. The research team also included an auditor who was an advanced graduate student who had recently completed a Master's thesis using the CQR methodology. The research mentor was for the study was an expert psychotherapist, and provided consultation and training to the principal investigator.

All members of the research team were trained in $\mathrm{CQR}$, and read the relevant literature. The principal investigator completed two practice interviews with experienced psychotherapists who were invited to serve as pilot interviewees. These interviews were supervised by the research mentor. The principal investigator trained the RAs in the CQR method, with attention to the following: the importance of speaking one's mind, the 
usefulness of considering alternative perspectives, a willingness to discuss disagreements, the importance of mutual respect, the value of the consensus process, and the necessity of attending to personal expectations and biases.

Prior to coding data, all members of the research team assessed and recorded their expectations and biases. Each member of the research team reviewed the relevant

literature and the study protocol, and documented what results they expected to find upon completion of the study. Team members also recorded the values and beliefs on which they base their expectations.

\section{B. The Measure}

Study data were collected using a semi-structured interview. The study interview consisted of a series of open-ended prompts that addressed the study's broad and specific questions listed above. These questions represented important themes emerging from the research literature on premature termination. The principal investigator and research mentor conducted an initial pilot interview, after which the interview protocol was refined for clarity and brevity. The principal investigator then conducted a second pilot interview with a practicing therapist recruited solely to test and refine the interview further. The final semi-structured interview protocol incorporated knowledge from the relevant literature with the experience from two pilot interviews, and feedback from two practicing psychotherapists (see Appendix A).

\section{Procedure}

Recruitment of participants. The principal investigator recruited participants through the public database of the American Board of Professional Psychologists (ABPP). The principal investigator contacted ABPP members, beginning with those in 
geographic proximity to the University of Massachusetts, Amherst, by email or phone. Potential participants were provided with a description of the study, and the opportunity to ask questions regarding its purposes and procedures. Willing participants, who met the screening criteria listed above, were scheduled for an in-person interview.

Interviews. The principal investigator conducted all interviews, each of which took place in the participant's psychotherapy office. Interviews were preceded by an informed consent process in which the participant reads and signs the study's Consent to Participate in Research form (see Appendix B). The confidentiality of participating therapists, and of their clients, was maintained through the use of pseudonyms and the omission of identifying information. Each interview concluded with a study debriefing during which the principal investigator repeated the purpose of the interview, asked if the participant had any questions or concerns, and provided the participant with a Study Debriefing Form (see Appendix C).

Transcription. Each study interview was transcribed by a member of the primary research team, and checked for accuracy by a different member of the research team. The confidentiality of transcriptions was maintained, and any identifying information was deleted from the transcripts. Interviews were transcribed verbatim, with the exception of sighs, laughs, stutters, non-language utterances ("er", "um", "ah") or fillers (“you know", "okay”).

The consensus process. Each member of the primary research team first examined the data independently, forming his or her own coding decisions based on the raw interview data. Team members then met to compare their coding decisions. The principal investigator facilitated a process during which members of the primary team 
discussed each coding decision until they agreed on the best possible coding of the data. In instances in which the best possible coding was unclear, team members referred back to the raw data and considered the range of possible coding decisions. Team members discussed any coding disagreement until they reached the best possible coding for the data. When a disagreement was not resolved by referring to the raw data, the team members reviewed the audio-tape of the interview to look for subtle indications of meaning. Throughout the consensus process, the principal investigator asked the team members to consider how their expectations and biases may have affected their decisions. The auditor checked the results of the consensus process to ensure that the team's decisions reflected the raw data, rather than a dysfunctional group process (i.e., groupthink, or one team member dominating the group process).

Coding domains and core ideas. Domains represent overarching topic areas that are distinct and yet, taken together, encompass the range of data gathered in the study. The principal investigator created an initial set of domains, based on the research literature and the interview protocol. Core ideas summarize what the participant has said, but "in fewer words and with more clarity" (Hill et al., 1997). The principal investigator identified and numbered core ideas in each interview. Each research team member then reviewed the data independently. Team members created core ideas using many of the participant's words, without adding or inferring meaning. Team members also assigned each core idea to an existing domain, or created a new domain when they believed it was more fitting. Information that was considered irrelevant to the domain was not abstracted. The primary team members then met to compare their coding, and to reach a consensus coding of the domains and core ideas. Data were only double-coded if 
absolutely necessary, and double-coding was avoided if at all possible. The resulting set of core ideas summarized each participant's responses within a given domain.

The research team began this process by coding the first interview as one group, with each team member coding the entire interview. Once the team had reached consensus coding for the first interview, team members broke into subgroups in order to code the remaining interviews, with each team member checking another for agreement. Throughout the process, the team members reviewed their consensual coding to ensure that the same set of domains were labeled and applied consistently across all interviews.

Auditing of domains and core ideas. The auditor checked the work of the research team for accuracy and bias. The job of the auditor was to check that the research team's consensus process had resulted in the best possible coding of the data, and had not been affected by team expectations, biases, or group dynamics such as group-think or deference to one group member. The auditor checked that the raw interview data had been placed into the most representative domains. The auditor checked that all of the important information in a domain was abstracted into its core ideas. The auditor checked that the core ideas were written concisely, and that they reflect the words of the participants. The auditor provided feedback to the primary team in the form of both specific and general recommendations. The research team members reviewed the auditor's feedback and decided as a group whether to accept or reject each recommendation with support from the raw data. Once audited, the initial coding of domains and core ideas was complete. The team members reviewed their coding of the first few interviews to ensure that they had applied consistent rules across all of the interviews. 


\section{Data Analysis}

Cross-analysis. The consensus coding resulted in a list of core ideas, taken from each interview, which were grouped by a set of domains that had been applied across all interviews. During cross-analysis, the research team used these domains to look across all interviews and identify categories of ideas that were common among all participants. First, core ideas from all interviews were grouped together under their shared domains. Next, each team member reviewed the core ideas under each domain individually, and clustered them into common categories. The following rules were used to categorize core ideas: (1) one core idea could be coded under multiple categories, (2) core ideas from one interview could be divided among different categories, (3) categories that represented only one or two core ideas could be combined with another similar category or else dropped, and (4) a category could be subdivided if it included different types of data. The primary team members then met to compare their cross-analyses, and to reach a consensus coding of these categories. During this process the research team members identified inconsistencies or ambiguities in some core ideas, and returned to the raw data in order to discuss the inconsistency, reach a consensus decision, and re-code the data.

Auditing of cross-analysis. The auditor again checked the work of the research team for accuracy and bias. The auditor reviewed the cross-analysis to ensure that each core idea fit under the specified category. To this end, the auditor checked the following: (1) that category labels captured the essential meaning of the core ideas that they contained, (2) that core ideas were not so dissimilar as to merit dividing categories, and (3) that similar categories were not better combined because of similar content. The auditor again provided feedback to the primary team in the form of specific and general 
recommendations which the research team reviewed and accepted or rejected based on the raw data. After the completion of the cross-analysis phase, all relevant sentences or phrases in the data were summarized in a core idea, grouped into a thematic domain, and represented in a meaningful category. 


\section{CHAPTER III}

\section{RESULTS}

The research team applied the CQR process to the research interviews, grouping the participants' data into domains (see Table 1), and then identifying categories of meaning that appeared across multiple interviews. The resulting categories are presented in six tables that contain thematically similar domains: clients' presenting problems (Table 2); the structure and format of treatment (Table 3); what went well in therapy (Table 4); problems that arose during therapy (Table 5); descriptions of how treatment ended (Table 6); and information pertaining to the therapists' professional development following the termination (Table 7). ${ }^{1}$

\footnotetext{
${ }^{1}$ Only a subset of the resulting domains and categories are presented here, as not all of the coded data were considered germane to the research questions (e.g., information on the therapists' training is not reported.)
} 
Table 1. The Final Set of Domains Organized Into Groups

\begin{tabular}{|c|c|}
\hline $\begin{array}{l}\text { Group of Domains } \\
\text { Domain }\end{array}$ & $\begin{array}{l}\text { Group of Domains } \\
\text { Domain }\end{array}$ \\
\hline Client's presentation & Structure of treatment \\
\hline \multirow[t]{2}{*}{ Client's presenting problem } & Duration of treatment \\
\hline & Frequency of sessions \\
\hline What went well in therapy & Therapist's strategies \\
\hline \multicolumn{2}{|l|}{ Clients' progress in treatment } \\
\hline Clients' strengths & Termination \\
\hline \multirow[t]{2}{*}{ Therapists' positive feelings toward the clients } & Therapists' foresight of the termination \\
\hline & How treatment ended \\
\hline \multicolumn{2}{|r|}{ Events following the termination } \\
\hline $\begin{array}{l}\text { Client circumstances that interfered } \\
\text { with therapy }\end{array}$ & $\begin{array}{l}\text { Personal impact of the termination on } \\
\text { the therapist }\end{array}$ \\
\hline $\begin{array}{l}\text { Problems with the client's readiness } \\
\text { or willingness }\end{array}$ & $\begin{array}{l}\text { How the therapist made sense of } \\
\text { the termination }\end{array}$ \\
\hline \multicolumn{2}{|l|}{ Client emotional reactions to therapy } \\
\hline Client absences from therapy & Therapists' professional development \\
\hline \multirow{5}{*}{$\begin{array}{l}\text { Problems with treatment } \\
\text { Mistakes made by the therapist } \\
\text { Problems in the therapeutic relationship } \\
\text { Therapist emotions that presented a challenge }\end{array}$} & What the therapist would do differently \\
\hline & T \\
\hline & $\begin{array}{l}\text { Therapists' remaining questions about } \\
\text { the case }\end{array}$ \\
\hline & $\begin{array}{l}\text { Lasting effects of the termination on } \\
\text { the therapists }\end{array}$ \\
\hline & Advice or lessons offered by the therapists \\
\hline
\end{tabular}

The research team reached the final set of domains through a process of repeated discussion and revision. The team began this process by creating an initial set of domains that aligned with the questions in the research interview, and then distinguishing between domains that contained the participating therapists' descriptions of their own experiences, and their reports of the clients and the clients' experiences. As the team attempted to code the interview data, we found that some of our initial domains remained conceptually distinct (i.e., client history, or advice offered by the therapist), while others proved to be unclear, or to overlap with one another (i.e., warning signs that the client would terminate, and therapist factors related to termination). The research team also discussed 
whether the grouping of the data should attempt to address questions that proved difficult to answer: Could the team distinguish between more and less subjective data? Must the team differentiate between information offered as certain and that offered as conjecture? Could the team consistently draw a line between the therapists' understanding at the time of the case vs. the therapists' understanding that was reached only upon reflection? How, with simple groupings, could the team faithfully represent therapists' report of cause-andeffect, or processes that took place over time? In the final cross-analysis, the research team focused instead on identifying common processes that emerged from the data (i.e., client behaviors that interfered with therapy, and mistakes made by the therapist). The final set of domains represents a "best possible" coding of the data set.

Following the CQR technique, we labeled the resulting categories to provide an indication of how common each category was evident in the 11 interviews. Adhering to the method and nomenclature used by Hill and colleagues (1997; 2005), we designated categories that emerged in all 11 interviews as general, in 6 to 10 interviews as typical, and in 3 to 5 interviews as variant. We dropped categories that applied to fewer than 3 cases. For the sake of readability, we use paraphrasing substitute language in the narrative section of this paper (e.g., general: "in all cases"; typical: "in most cases"; variant: "in fewer cases"). 
Table 2. Domains and Categories Related to the Clients' Presentation

\begin{tabular}{lr|lr}
\hline $\begin{array}{l}\text { Domain } \\
\text { Category }\end{array}$ & $\begin{array}{r}\text { Number of Cases } \\
(\mathrm{n}=11)\end{array}$ & $\begin{array}{l}\text { Domain } \\
\text { Category }\end{array}$ & $\begin{array}{r}\text { Number of Cases } \\
(\mathrm{n}=11)\end{array}$ \\
\hline Clients' presentation & & Clients' presentation (continued...) & \\
Depression and other mood disturbance & 11 & Problems with sense of self & 5 \\
Interpersonal problems & 11 & Ineffective previous treatment & 5 \\
Damage from childhood abuse and trauma & 8 & Problems in work or school & 5 \\
Characterological problem & 8 & Substance abuse & 4 \\
Unresolved personal conflicts & 7 & Loss & 4 \\
Repetitive and problematic patterns & 6 & Suicidal thoughts & 4 \\
of behavior & & Limited range of emotions & 3 \\
& & \\
\end{tabular}

Note. Categories that apply to fewer than 3 cases are not shown.

\section{A. Clients' Presentation}

Study therapists reported that clients presented with a range of concurrent problems. In all cases, therapists recalled that their clients were experiencing both mood disturbance (most commonly depression), and interpersonal problems (e.g., marital conflict). In most cases, therapists said that their clients were troubled by damage from childhood abuse and trauma, characterological problems (e.g., narcissism), unresolved personal conflicts (e.g., spiritual crisis), or repetitive and problematic patterns of behaviors (e.g., cycles of confrontation and withdrawal). In fewer cases, therapists reported that clients presented with problems in other areas including their sense of self (e.g., low self-esteem), ineffective previous treatments, problems in school or work, substance abuse, loss (e.g., grief over the death of a child), suicidal thoughts, or limited range of emotional experience (e.g., "He couldn’t let himself feel."). 
Table 3. Domains and Categories Related to the Structure of Treatment

\begin{tabular}{lr|lr}
\hline $\begin{array}{l}\text { Domain } \\
\text { Category }\end{array}$ & $\begin{array}{r}\text { Number of Cases } \\
(\mathrm{n}=11)\end{array}$ & $\begin{array}{l}\text { Domain } \\
\text { Category }\end{array}$ & $\begin{array}{r}\text { Number of Cases } \\
(\mathrm{n}=11)\end{array}$ \\
\hline Duration of treatment & 6 & Therapists' strategies \\
Longer than 6 months & 4 & Adrovided support or empathy & 9 \\
Less than or equal to 6 months & & Facilitated insight & 9 \\
& & Proceeded slowly, and carefully & 6 \\
Frequency of sessions & 3 & Addressed the therapeutic relationship & 5 \\
Weekly & $* 2$ & & \\
Every other week & $* 2$ & & \\
Twice per week & & & \\
& & & \\
\end{tabular}

*Note. Categories that apply to fewer than 3 cases are shown in this table due to high variability in session frequency.

\section{B. Duration of Treatment, and Frequency of Sessions}

In describing the structure of therapy, participating therapists stated that in most cases the duration of treatment was longer than six months. In fewer cases, the frequency of treatment was weekly, every other week, or twice per week.

\section{Therapists' Strategies}

Therapists reported using a number of complementary therapeutic strategies. In most cases, therapists attempted to provide support (e.g., through listening and validation), address presenting problems or symptoms (e.g., by focusing on the client's functioning), facilitate insight (e.g., by "getting him to look at how he was continually trying to fill this empty hole with drugs and alcohol."), and to proceed slowly or carefully. In fewer cases, therapists described efforts to address problems in their therapeutic relationship with the clients (e.g., "You try to build trust, and you try to get to some kind of relationship with the parts that are coming into therapy."). 
Table 4. Domains and Categories Related to What Went Well in Therapy

\begin{tabular}{lr|lr}
\hline $\begin{array}{l}\text { Domain } \\
\text { Category }\end{array}$ & $\begin{array}{r}\text { Number of Cases } \\
(\mathrm{n}=11)\end{array}$ & $\begin{array}{l}\text { Domain } \\
\text { Category }\end{array}$ & $\begin{array}{r}\text { Number of Cases } \\
(\mathrm{n}=11)\end{array}$ \\
\hline Clients' progress in treatment & 8 & Clients' strengths \\
Engaged in therapy & 8 & Client was intelligent & 4 \\
Formed a relationship with the therapist & 6 & \\
Gained insight & 5 & Therapists' positive feelings toward the clients \\
Improved relationships & 4 & Therapist felt positively toward the client \\
Reduced symptom severity & 4 & \\
Explored difficult feelings & 3 & \\
Improved functioning or coping & 3 & \\
Processed abuse or trauma & & \\
\end{tabular}

Note. Categories that apply to fewer than 3 cases are not shown.

\section{Client Progress in Treatment}

Although all of the cases discussed ended in premature termination, study therapists did note a number of positive aspects of therapy. The therapists believed that their clients made substantial progress over the course of therapy. In most cases, therapists noted that their clients had successfully engaged in the process of therapy (e.g., "He kept on coming back, he never left the sessions early, he said he liked them."), and had formed a relationship with the therapists (e.g., the client and therapist established mutual trust). In fewer cases, therapists reported that their clients had gained some insight into their problems (e.g., "He became much more aware of what he was doing."), experienced reductions in symptom severity (e.g., "She perked up some."), improved their relationships with others, explored difficult feelings (e.g., expressed loss or guilt), began to function or cope better (e.g., "She began to feel better by doing more vigorous exercise."), or began to process early abuse and trauma (e.g., "There was a certain degree of relief in explaining her story to someone who would be willing listen to it.”). 


\section{E. Client Strengths and Therapists' Positive Feelings toward the Clients}

In addition to describing progress, a few therapists noted other factors that boded well for treatment. In fewer cases, therapists described their clients as intelligent, or likeable. Also in fewer cases, therapists said that they felt positively towards their clients (e.g., the therapist liked, or was committed to, the client). 
Table 5. Domains and Categories Related to Problems in Therapy

\begin{tabular}{|c|c|c|c|}
\hline $\begin{array}{cr}\text { Domain } & \text { Number of Cas } \\
\text { Category } & (\mathrm{n}=1 \\
\end{array}$ & & $\begin{array}{r}\text { Number of Case } \\
(\mathrm{n}=11\end{array}$ & \\
\hline Client circumstances that interfered with & & Problems with treatment & \\
\hline therapy & & Treatment resulted in incomplete or & 8 \\
\hline Family problems or lack of support & 5 & inconsistent progress & \\
\hline Problems with work or finances & 4 & Therapist's intervention was ineffective & 7 \\
\hline Geographic problems & 3 & $\begin{array}{l}\text { Client had difficulty with changes in the } \\
\text { structure of treatment }\end{array}$ & 7 \\
\hline & & $\begin{array}{l}\text { Client's symptoms worsened as a result } \\
\text { of therapy }\end{array}$ & 3 \\
\hline $\begin{array}{l}\text { Problems with the clients' readiness or } \\
\text { willingness }\end{array}$ & & & \\
\hline Client felt threatened by progress & 9 & Mistakes made by the therapists & \\
\hline Client found the work of therapy too difficult & 8 & Therapist failed to see a problem & 7 \\
\hline Client never fully committed to treatment & 5 & Therapist failed to address a problem & 6 \\
\hline & & $\begin{array}{l}\text { Therapist did not give the client what } \\
\text { he or she needed }\end{array}$ & 5 \\
\hline & & Therapist allowed his or her feelings to & 4 \\
\hline Client emotional reactions to therapy & & interfere & \\
\hline Client felt: & & & \\
\hline Overwhelmed or vulnerable & 7 & Problems in the therapeutic relationship & \\
\hline Hurt or angry & 6 & Client had difficulty connecting & 8 \\
\hline Dissatisfied with treatment or the therapist & 6 & Client and therapist disagreed & 7 \\
\hline & & $\begin{array}{l}\text { Emotional bond between the client and the } \\
\text { therapist was damaged, or unrepaired }\end{array}$ & 7 \\
\hline Client absences from therapy & & Client enacted transference & 6 \\
\hline Client did not show for sessions & 7 & $\begin{array}{l}\text { Client and therapist held divergent } \\
\text { Expectations about therapy }\end{array}$ & 5 \\
\hline $\begin{array}{l}\text { Client was away from therapy for an } \\
\text { extended period of time }\end{array}$ & 5 & Therapist countertransference was a problem & \\
\hline Client cancelled sessions & 3 & & \\
\hline & & Therapist emotions that presented a challenge & \\
\hline & & Therapist felt: & \\
\hline & & Frustrated, discouraged, or burnt-out & 6 \\
\hline & & Guilty or sad & 5 \\
\hline & & Anxious & 4 \\
\hline & & Surprised & 4 \\
\hline
\end{tabular}

Note. Categories that apply to fewer than 3 cases are not shown. 


\section{F. Client Circumstances That Interfered with Therapy}

Therapists identified problems in their clients' lives outside of treatment that interfered with the course of therapy. In fewer cases, therapists reported that their client had difficulty in therapy due to problems with their families (e.g., "[Therapy] really ended largely because his wife got totally fed up.’), problems with work or finances (e.g., "money was tight"), or geographic challenges (e.g., "It was a 60-mile round-trip.”).

\section{G. Problems with Clients' Readiness or Willingness}

Therapists described their clients as unready or unwilling to engage in the work of therapy. In most cases, therapists reported that their clients felt threatened by progress (e.g., "It was too threatening for her to think about herself."), found the work of therapy too difficult (e.g., "It became easier to just retreat to the status quo."), or became defensive or avoidant in response to therapy (e.g., client was unwilling to give up a "defensive stance"). In fewer cases, therapists felt that their clients never fully engaged in therapy to begin with (e.g., the client was "always on the verge of leaving").

\section{H. Client Emotional Reactions to Therapy}

Therapists recalled that, as a result of treatment, clients experienced a number of difficult emotions. In most cases, therapists reported that their clients felt overwhelmed or vulnerable (e.g., "I think she was just flooded and overwhelmed."), hurt or angry (e.g., the client felt emotionally injured by the therapist), or dissatisfied (e.g. "He knew that I was trying, and had his best interest in mind, but I still didn't seem like the guy he really wanted to be his therapist."). In fewer cases, therapists noted that their clients felt a sense of hopelessness or desire to give up on treatment (e.g., "She was determinedly hopeless."). 


\section{Client Absences from Therapy}

Many therapists reported that their clients failed to keep appointments. In most cases, therapists said that their clients failed to show for therapy at times. In fewer cases, therapists said that their clients were absent from therapy for extended periods of time (e.g., weeks or months), or cancelled sessions periodically.

\section{J. Problems with Treatment}

Therapists also attributed the premature termination to problems with the treatment itself, or to their clients' responses to treatment. In most cases, therapists said that their interventions were ineffective (e.g., "I was just doing what I do, and it didn't work.”), that treatment resulted in incomplete or inconsistent progress (e.g., “...he never got to a point of feeling euthymic."), or that their clients had difficulty with a change in the structure of treatment (e.g. "I think one of the things that created the termination later was my attempt to utilize his family as an intervention.”). In fewer cases, therapists reported that their clients' symptoms worsened as a result of therapy (e.g., the client escalated his drug use in response to exploratory work in therapy).

\section{K. Mistakes Made By the Therapist}

Many therapists felt that they had made mistakes in the course of treatment. In most cases, therapists believed that they had either failed to recognize a problem in therapy (e.g., "I made some mistakes and I didn't anticipate everything."), or failed to sufficiently address a problem (e.g., "It was a battle that I didn't want to admit that I should have had. I never fought them about [having more frequent sessions].”). In fewer cases, therapists felt that they had failed to accommodate their clients' needs in therapy (e.g., "not providing enough containment in some way, or thinking that containment is 
solely through listening"), or that they had allowed their own emotions to interfere with treatment (e.g., "I think I was quite eager to make a connection to her, maybe too eager in some way.").

\section{Problems in the Therapeutic Relationship}

Many therapists also reported that they had strained relationships with their clients. $^{2}$ In most cases, therapists said that they and their clients had difficulty forming a therapeutic relationship (e.g., "I found that with him we never really established a comfortable connection."), disagreed about the goals or tasks of therapy (e.g. "He would look at me like 'that was the dumbest idea' he ever heard."), or had an emotional bond that was damaged in the course of treatment (e.g., the therapist forgot a session, and the client "was so hurt and pained,... in some way she never really forgave me for that."). In fewer cases, therapists said that they and their clients held different expectations about what therapy would entail (e.g., "Maybe she felt like I was expecting too much of her and not enough of him."), or that the therapeutic relationship became strained by the client's transference (e.g., "He left me in this way that was so much a reenactment, so much splitting, that he couldn't really see... the whole picture."), or their own countertransference (e.g., "There's the countertransference; trying to make him move along.").

\section{Therapist Emotions That Presented a Challenge}

Therapists acknowledged that they also experienced a number of difficult emotions during treatment. In most cases, therapists reported feeling frustrated, or burnt-

\footnotetext{
${ }^{2}$ Categories in the domain of problems in the therapeutic relationship were structured based on the relevant literature in general, and Bordin's (1979) conceptualization of the therapeutic relationship in particular.
} 
out while treating their clients (e.g., "She had used me up"). In fewer cases, therapists reported feeling sad or guilty (e.g., "I felt terrible.”), conflicted (e.g., "My job is to help the individuals in the groups, but also to do the work that the group needs to do. And here was this group issue that wasn't being addressed when he was in the room."), anxious (e.g., "I think maybe there was a cautiousness in me not wanting to make any mistakes with her."), or surprised (e.g., "I was a little surprised to see him coming on that regular a basis.").

Table 6. Domains and Categories Related to the Termination

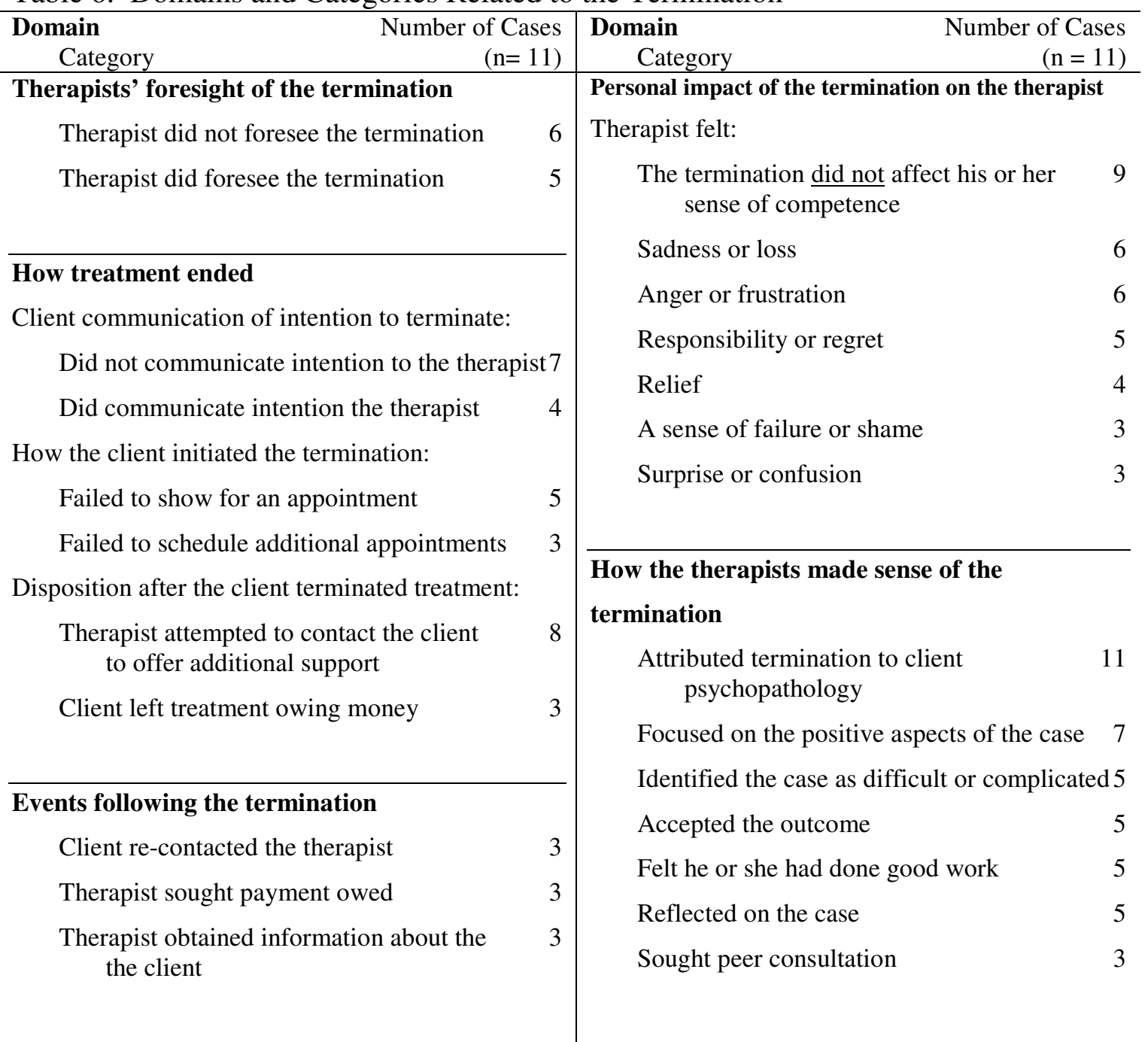

Note. Categories that apply to fewer than 3 cases are not shown. 


\section{N. Therapists' Foresight of the Termination}

Study therapists were almost evenly split between those who anticipated their clients' premature termination, and those who did not see it coming. In most cases, therapists said that they had not anticipated their clients' departures (e.g., "I wouldn't have guessed it. I actually thought he had a very strong connection", or "I was blindsided."). In fewer cases, therapists said that they saw warning signs that their clients might terminate therapy prematurely (e.g., "There were a couple times that she indicated that she could bail if things got bad.").

\section{O. How Treatment Ended}

Clients ended treatment in a variety of ways. In most cases, clients did not tell their therapists that they intended to end treatment (e.g., "There was no quote-unquote termination, or winding down. It just stopped.”). In fewer cases, they did communicate their intention (e.g., "He didn't really want to talk about it. And then when I urged him to come in, he said he was getting worse and worse with every treatment."). Also in fewer cases, with regard to how they initiated the termination, clients either failed to show for a scheduled appointment, or failed to schedule additional appointments. In most cases, therapists attempted to contact their former clients (e.g., by letter, or e-mail) to acknowledge the termination, and to offer future services or treatment referrals. Lastly, in fewer cases, therapists reported that their clients left treatment owing money.

\section{P. Events Following the Termination}

Many of the therapists had some interaction with, or knowledge of, their former clients after the termination. In fewer cases, therapists contacted their former clients in order to recover unpaid fees (e.g., "I had to call and talk to them about [their bill], and 
ended up sending them a letter saying that I was going to regrettably have to take some legal actions if they didn't pay their bill."), obtained information about their former clients through secondary sources (e.g., the client's family contacted the therapist after the termination), or were contacted by their former clients for additional support of some kind (e.g., for further treatment, a referral, or a letter of reference).

\section{Q. Personal Impact of the Termination on the Therapists}

Therapists reported experiencing a wide range of thoughts and feelings in response to their clients' departures. In most cases, therapists felt the termination had not affected their sense of competence (e.g., "I didn't feel it had anything to do with my competence. I thought he would run into this no matter what."), a sense of sadness or loss (e.g., "I was disappointed...really disappointed."), or of anger or frustration (e.g., "I find myself a little angry, I mean if I think about it, because I took it seriously, and she didn't."). In fewer cases, therapists felt a sense of responsibility or regret (e.g., "I felt guilty, what did I do wrong?”), relief (e.g., "I think I, truth be told, I was relieved; I was like, okay, it's time for me to move on too."), failure or shame (e.g., "I felt embarrassed or ashamed a little bit that this would happen."), or of surprise or confusion (e.g., "I was surprised by the abrupt nature of the termination.").

\section{R. How the Therapists Made Sense of the Termination}

Therapists responded to premature termination with a variety of thoughts and coping strategies. In all cases, therapists placed the responsibility for the termination on their former clients (e.g., "He was just plain difficult. Many people wouldn’t be spending this kind of time thinking about a case like that."). In most cases, therapists highlighted the positive aspects of the case (e.g., "Maybe the progress was her ending treatment."). 
In fewer cases, therapists identified their cases as particularly difficult or complicated (e.g., "she took an unusual amount of work"), chose to accept the outcome (e.g., "Sometimes that's what we have to do; we have to be left."), judged their work positively (e.g., "I did, I think, a very good therapy with a very difficult client."), spent time reflecting on the case (e.g., "I thought about if I had done this, or if I had said that, or what have you"), or consulted with colleagues about the case.

Table 7. Domains and Categories Related to the Therapists' Professional Development

\begin{tabular}{|c|c|c|c|}
\hline \multicolumn{2}{|l|}{$\begin{array}{cr}\text { Domain } & \text { Number of Cases } \\
\text { Category } & (\mathrm{n}=11) \\
\end{array}$} & \multicolumn{2}{|l|}{$\begin{array}{cr}\text { Domain } & \text { Number of Cases } \\
\text { Category } & (\mathrm{n}=11) \\
\end{array}$} \\
\hline \multirow{2}{*}{\multicolumn{2}{|c|}{$\begin{array}{l}\text { What therapists would do differently in } \\
\text { retrospect? }\end{array}$}} & \multicolumn{2}{|l|}{ Lasting effects of the termination on the therapists } \\
\hline & & A sense of uncertainty & 7 \\
\hline Would offer the client more support & 5 & Curiosity about the client & 4 \\
\hline Would do nothing different; success was & 4 & Decreased confidence & 4 \\
\hline Would focus more on symptom reduction & 3 & Lingering emotions & 4 \\
\hline Would focus more on exploring issues & 3 & & \\
\hline $\begin{array}{l}\text { Would change the timing or order of } \\
\text { interventions }\end{array}$ & 3 & $\begin{array}{l}\text { Advice or lessons offered by the therapists } \\
\text { Be prepared for difficult clients }\end{array}$ & 6 \\
\hline & & Recognize problems with client & 6 \\
\hline Therapists' remaining questions about the case & & & \\
\hline $\begin{array}{l}\text { How can the therapist improve upon the } \\
\text { treatment that he or she offers? }\end{array}$ & 7 & $\begin{array}{l}\text { Know your strengths and weaknesses } \\
\text { as a therapist }\end{array}$ & 4 \\
\hline What went wrong in the case? & 5 & Consult with peers & 4 \\
\hline How is the client doing today? & 5 & $\begin{array}{l}\text { Recognize that the therapeutic relationship } \\
\text { is important }\end{array}$ & 4 \\
\hline What was the value of therapy for the client? & 3 & Address disagreements with clients & 4 \\
\hline & & $\begin{array}{l}\text { Be careful when a client has } \\
\text { a history of trauma or abuse }\end{array}$ & 3 \\
\hline
\end{tabular}

Note. Categories that apply to fewer than 3 cases are not shown.

\section{S. What Therapists Would Do Differently in Retrospect}

Therapists offered a variety of corrections they would make to their approach in retrospect. In fewer cases, therapists said that they would adjust their interventions by being more supportive of their clients (e.g., "I might have needed to be less active, more supportive in some ways."), changing the timing or order of their interventions (e.g., 
aimed to reduce symptoms first, before beginning exploratory work), focusing more on reducing their clients' symptoms (e.g., addressing ongoing substance abuse), or doing more exploration of the cause of their clients' problems (e.g., "maybe get a little more at the roots of her feelings about her parents separating"). Also in fewer cases, some therapists felt that there was nothing they could have done differently to affect the outcome.

\section{T. Therapists' Remaining Questions about the Case}

Therapists in the sample had several unanswered questions in the wake of their clients' terminations. In most cases, therapists questioned how could they improve upon the treatment they offer (e.g., "The challenge of any case...is to find out what went wrong... and to see if I can continue to improve helping people."), or what had gone wrong (e.g., "What should I have done differently?"). In fewer cases, therapists wondered how their former clients' are doing now (e.g., "I wonder how this woman is doing. I wonder if she found another therapist. "), or whether their client's felt therapy was helpful in any way (e.g., "What meaning did therapy have for her, because we don't know.").

\section{U. Lasting Effects of the Termination on the Therapist}

Therapists reported that they experienced enduring feelings in the wake of the terminations. In most cases, therapists experienced a lingering sense of uncertainty about what went wrong, or how the termination could have been avoided (e.g., "I can only guess; I don't know"). In fewer cases, therapists reported that they felt lasting effects on their confidence (e.g., "I'm not sure I could [be less anxious about injuring the client], but that's what I would hope."), ongoing curiosity about their former clients (e.g., "I am still 
curious. I don't know if I'll ever get the answer."), or lingering emotions about the case (e.g., regrets, anger at the client, or worry for the client's well-being).

\section{Advice or Lessons Offered By the Therapist}

Therapists offered advice and lessons based on their experiences with their former clients. In most cases, therapists highlighted the importance of being prepared for difficult clients (e.g., "There are people... you're going to hate. There are going to be things that the patient sets off in you which are like small nuclear explosions."), or of being able to recognize and address problems as they arise in therapy (e.g., "even say directly, I'm not sure where to go; we've tried this, we've tried that, what do you think?"). In fewer cases, therapists emphasized the value of knowing one's strengths and vulnerabilities as a therapist (e.g., "It's hard...to have that sort of private ambition."), recognizing the importance of the therapeutic relationship (e.g., "Sometimes people leave because...the chemistry is not right."), seeking out peer consultation and support (e.g., "It is important to have relationships with colleagues...because otherwise you are moving off in the direction of...solipsism.”), identifying and discussing disagreements with clients (e.g., "Try and check out how their expectations are going in terms of what's actually happening in therapy."), or being particularly careful when treating clients who have experienced early abuse or trauma (e.g., "Boundaries are crucial when you didn't have any growing up.”). 


\section{CHAPTER IV}

\section{DISCUSSION}

The present study offers a rare glimpse of how eleven therapists have understood and learned from cases of premature termination. In this section I will first summarize the common narrative drawn from the eleven interviews, next discuss several themes which emerged, then note the limitations of the study, and conclude with comments on implications for psychotherapy research, and clinical practice.

\section{A. Common Narrative}

Although each therapist told a unique story, together their descriptions converge into a set of similar experiences. Therapists reported that their clients presented to treatment with various problems including mood disturbance, characterological and interpersonal difficulties, and histories of unresolved trauma or abuse. In response to these problems, the therapists used a range of approaches in which they aimed to alleviate their clients' symptoms, facilitate the development of insight, and provide empathy and support.

In identifying problems that led to premature termination, therapists described an intersection of factors which they attributed to both their clients and themselves. Some therapists shared the view that progress had been limited because their clients faced stressful life circumstances, or were unready or unwilling to change. Most therapists also recognized the role that they themselves had played in contributing to the premature terminations. Some spoke of the mistakes they had made, and others acknowledged their failure to recognize problems in the treatment. Highlighting the interpersonal nature of psychotherapy, all therapists indicated that strains in the client-therapist relationship also 
played a central role in the outcome. Therapists described how difficulties in treatment, such as client defensiveness and therapist frustration, had caused rifts in the therapeutic relationship. Complicating the story, therapists also made the opposite attribution, namely, that problems in the client-therapist relationship, such as disagreements and interpersonal conflict, had given rise to other difficulties in treatment.

Although these therapists could identify problems with treatment in retrospect, only some stated that they had seen warning signs that their clients might leave while treatment was in process. Especially troubling for therapists were the commonly occurring instances in which clients had not spoken about their intention to discontinue treatment, but simply had failed to show for an appointment without any subsequent communication. In such circumstances, therapists attempted to contact their clients, if only to acknowledge the termination and invite their clients to return to treatment in the future. Therapists recalled feeling a mixture of sadness, anger, regret, and relief in the wake of their clients' abrupt departures. For the most part, the therapists reported little detrimental impact of such terminations on their sense of professional competence. Unaffected therapists attributed this invulnerability to their many years of clinical experience, which may have insulated them from clinical events that were disappointing or perplexing. Either at the time of the premature termination, or in the period that followed, therapists held their clients, not themselves, responsible for the end of treatment.

After reflecting on their cases, therapists were able to draw valuable lessons and advice from their experiences. All identified adjustments they could have made which might have altered the outcome. In offering advice, they emphasized that therapists 
should be prepared to work with difficult clients, be able to maintain strong therapeutic relationships, and be aware of their own professional and personal weaknesses. In the end, even though they may have reached an understanding of the case and a sense of how they could improve, most of the interviewees remained curious about their former clients, and continued to wonder what had gone wrong.

\section{B. Clients' Presentation and the Structure of Treatment}

In comparing the participating therapists' stories, a number of meaningful themes emerged. With regard to the conditions under which treatment began, the cases described were typical for clinical practice. Therapists described clients who came to treatment with compound presenting problems, a fact that is not surprising considering the high rate of comorbidity in clinical samples (Kessler, Chiu, Demler, \& Walters, 2005). In addition, therapists employed a variety of strategies to address their clients' concerns, as is common for contemporary therapists, up to a third of whom identify their approach to psychotherapy as integrative or eclectic (Norcross, 2005).

Contrary to what one might expect, no pattern emerged with regard to the frequency and duration of therapy sessions. One therapist, a trained psychoanalyst, commented that session limits imposed by managed care have made forming an intense therapeutic relationship more difficult because client and therapist are typically unable to meet multiple times per week. Despite this therapist's concerns, clinicians in the study described cases that ended in premature termination after twice-per-week sessions just as often as after weekly or twice-monthly sessions. With regard to duration, the interviews included only cases in which clients remained in treatment for at least four sessions, in light of research that distinguishes between clients who engage in therapy before 
terminating prematurely and those who leave before treatment has truly begun (Connell, Grant, and Mullin, 2006; Derisley \& Reynolds, 2000; Frayn, 2008). Similar to the variability in session frequency, some clients left therapy after years of treatment, but just as many left after only a few months.

\section{What Went Well}

Even though most clinicians would consider premature termination as disappointing, the interviewees generally characterized their cases as partially successful. All therapists but one reported that their clients had engaged in both the work of therapy and the therapeutic relationship, and had made progress in multiple spheres before ending treatment. One therapist reported that over the course of treatment his client, a graduate student, had improved from being unable to finish his academic work at the beginning of treatment to completing his comprehensive exams by the time he terminated therapy.

Although clients made significant gains in treatment, most therapists described their clients' progress as inconsistent or incomplete. In the case of the graduate student, although the client had made functional gains, he remained unhappy and unable to take pleasure in his accomplishments. The therapist reported that this client had felt discouraged by the disparity between his improved functioning and his unchanged emotional state, and had become increasingly dissatisfied with therapy and the therapist. Another therapist recalled that, although she was able to help her client to better manage interpersonal relationships, she ultimately felt discouraged by her client's lack of progress. Previous research has implicated client and therapist dissatisfaction with treatment as markers of trouble in the therapeutic relationship (Safran \& Muran, 1996), and principal reasons for premature termination (Pekarik, 1992; Reis and Brown, 1999). 
Although the experiences described by these therapists do not indicate whether inconsistent progress causes dissatisfaction with treatment, or vice versa, the conclusion can be drawn that clients and therapists can become dissatisfied with treatment, even when some degree of progress occurs.

\section{Problems in Therapy}

Study therapists readily described a wide range of problems that may have precipitated their clients' early departures from treatment, with most of the clinicians beginning their discussion of problems in treatment with descriptions of how their clients' psychopathology contributed to the end of therapy. Even though therapists were aware of obstacles to therapeutic progress, they did not always see them as warning signs that their clients might leave treatment prematurely. Some therapists recalled that their clients had experienced difficulty engaging in the therapeutic relationship early in treatment. Many noted that their clients had felt threatened by change, and that treatment interventions were ineffective. Although in retrospect they identified these problems as signs of later trouble, therapists reported that they had either failed to address these problems sufficiently, or in some cases had failed at the time to recognize them as threats to treatment.

The fact that therapists were aware of problems in treatment and did not see them as indications that therapy could fail is perhaps understandable. Psychotherapy scholars conceptualize some treatment difficulties, such as client defensiveness or resistance, as natural steps in the process of psychological change (Meissner, 1996; Safran \& Muran, 2000). In the words of one participant, "People have their defenses for good reason." As another participant put it, "Resistance doesn't scare me; resistance is part of therapy, but 
when it becomes overwhelming, then you can't continue." We are left with another difficult question: How can a therapist differentiate between obstructions in treatment that are natural, and those that interfere with the foundations of therapy? Perhaps problems in therapy are both natural and fundamentally challenging. Researchers who study the therapeutic relationship have suggested that the client-therapist bond is likely to weaken or become strained at times, and that recovery from these periods is the hallmark of a successful treatment (Gelso \& Carter, 1994). From this perspective, therapists face the paradoxical challenges of having to instigate conflicts that threaten their clients' participation in therapy, while also working to resolve those very same conflicts.

An awareness of the therapeutic relationship is important to understanding why some clients terminate therapy prematurely. Bordin (1979) suggested that relationships between clients and therapists could be understood in terms of three features: "an agreement on goals, an assignment of task or a series of tasks, and the development of bonds" (p. 253). Bordin (1994), as well other scholars (Frayn, 2008; Reis \& Brown, 1999; Safran \& Muran, 1996), stated that problems in the therapeutic alliance could lead to early termination from therapy. Several researchers have established preliminary evidence of an association between poorer therapeutic alliance and premature termination (Samstag et al., 1998; Tryon \& Kane, 1990, 1993).

Several issues regarding problems in therapy warrant consideration given the interpersonal nature of psychotherapy. First, explanations for termination that focus only on the client or the therapist may fail to account for important relational factors. Second, clients and therapists have distinct and subjective experiences of the treatment process, and understand problems in treatment differently. Third, once treatment has ended 
prematurely, and the two parties have gone their separate ways, a client or therapist can only access his or her personal perspective in attempting to reflect on the termination and learn from what went wrong. In the present study, members of the research team attempted to keep these complexities in mind, resisting the tendency to assign responsibility for the termination to either client or therapist; rather, attempts were made to understand the nuances of each story shared by each therapist.

In addition to identifying persistent obstacles to treatment, several therapists described specific events which damaged their relationships with clients and thereby precipitated the premature termination. One such event is the occurrence of a disagreement between the client and the therapist. For example, one therapist explained that his client had created a "battle for the structure of therapy" by repeatedly rejecting his recommendation that she consider taking medication to alleviate her symptoms of depression. In another case a therapist did not support his client's request for prescription medication, leading the client to voice his dissatisfaction and terminate treatment. The therapists in both cases felt that these disagreements had played a pivotal role in their clients' subsequent terminations.

Bordin's (1979) model of the therapeutic relationship can be used to explain how clinical events such as disagreements could affect treatment. He conceptualized a portion of the therapeutic relationship as comprised of the rational agreement between client and therapist on the tasks and goals of treatment. According to Bordin's model, disagreements are problematic when they indicate that the client and therapist hold conflicting beliefs about what therapy should involve, and how treatment will lead to change. Thus, disagreements would likely complicate practical matters in therapy such 
as treatment planning. Bordin conceptualized a related but distinct part of the therapeutic relationship as the emotional bond that connects the client and therapist, and saw these two aspects of the relationship as interdependent. As such, disagreements could also negatively impact the bond that connects the client and therapist by diminishing their shared sense of connection and trust.

Although rarely discussed in the literature, a mistake on the part of the therapist is another event that can have a powerful impact on the outcome of treatment, because a mistake can cause wounds in the therapeutic relationship that are extremely difficult to heal. Some therapists in the study judged that they had made mistakes by failing to recognize or address a problem in treatment. Other therapists reported that they had made more overt mistakes, such as offering too much advice, allowing their feelings about the client to interfere with treatment, or forgetting to meet their client for a session. Therapists explained that their mistakes led their clients to feel hurt, angry, and dissatisfied. They found it difficult to repair the damage caused by their mistakes. One therapist who forgot to show for a session said with regret, "Something was lost that was really hard to regain, if not impossible." Such mistakes may violate a client's unstated expectations that the therapist can be relied upon to be professional and to have expert knowledge; thus, clients view the mistake as a disruption in an unspoken agreement about the therapeutic framework, and a break in trust that damages the emotional bond between client and therapist.

Sometimes a change in the structure of treatment can negatively impact the outcome of treatment, and only in retrospect does the therapist come to see the decision to augment treatment as a mistake. For example, one therapist brought his client into 
concurrent group therapy in order to help the client address a longstanding identity conflict. The client struggled to make progress in group, and the group members came to believe that the client simply did not want to face reality and change. When the group members, facilitated by the therapist, expressed their frustration, the client felt hurt and betrayed by both the group and the therapist. The therapist in turn felt frustrated, and regretted his decision to bring the client into group; consequently, their working relationship suffered a blow from which it never recovered.

Some clients may be more sensitive to therapists' mistakes than others. The therapist in the example above explained how the damage to the therapeutic relationship which resulted from his mistake was exacerbated by his client's psychopathology:

In effect, he was re-doing what he did with his family. They hurt him, and he couldn't really differentiate the way that I had hurt him, or the way he felt hurt by me and the way that he was hurt by his family. He couldn't differentiate that his family never took responsibility... and that I did.

Several therapists in the study noted that their clients were especially difficult to form relationships with and were likely to terminate prematurely, because they had histories of trauma and abuse. In their clinical guidelines for responding to alliance ruptures, Safran and Muran (2000) support the notion that clients with traumatic pasts may be more vulnerable to alliance problems.

In addition to being attuned to the vulnerabilities of clients, therapists must also be attentive to the ways in which their own reactions and feelings can impact their work with clients. Many therapists in the study acknowledged that their clients' seeming inability or unwillingness to change led them to feel frustrated and burnt out. The therapist mentioned above who had forgotten to come to a session explained that, despite her commitment to the client, she had become frustrated in the face of her client's 
"determined helplessness." This therapist recalled that by the last sessions, "I was no longer looking forward to seeing [the client]." The fact that therapists can become tired and frustrated by their work is not surprising given recognition in the literature that burnout is a hazard attributed to the profession (Fleischer \& Wissler, 1985). In a related study, Piper and his colleagues (1999) examined sessions preceding dropout and found therapists and clients to be engaged in an unproductive pattern of resistance and ineffective transference interpretation irrespective of the therapist's level of experience. Therapists bear a responsibility to sustain an awareness of their level of professional fatigue, and to judge when that fatigue could impair their work (Miller, 1998).

Less often discussed in the literature are the personal vulnerabilities of therapists. Just as therapists are susceptible to making mistakes and to feeling frustration, they may also experience feelings of fear, guilt, shame, or various other emotions as the result of treatment. One therapist acknowledged that she became highly interested in her client's story, began to worry about the effect that her own intensity would have on her client, and attempted to conceal her curiosity. The therapist recalled that later, when her client's symptoms worsened, she wondered if she had contributed to her client's difficulty in treatment, and began to worry about how treatment failure would be perceived by her peers. In her words, "I thought, I botched this, and I'm not going to get any more referrals." Therapists' reactions can offer important information about how others may experience their clients, and therapists benefit when they attend to their own emotions over the course of treatment (e.g., Kimerling, Zeiss, \& Zeiss 2000; Reilly, 2000). The work of therapists can be complicated by the therapist's personal issues, which they 
should strive to understand, and to manage in the service of their clients (Guy, 2000; Norcross, 2000).

\section{E. Termination}

Therapists were not always able to predict that their clients would leave treatment prematurely. Roughly half of the participants in the study reported that they had anticipated their clients' departures, citing indications that their clients were becoming hopeless or frustrated, or that their clients' symptoms were worsening. The therapists who had not foreseen the premature termination also reported seeing similar signs of problems in therapy, although they had not viewed their clients to be at risk of leaving treatment. The fact that only some therapists had predicted their clients' premature terminations raises a number of questions: (1) Can therapists accurately predict whether their clients will terminate prematurely? (2) To what extent do factors such as the strength of the client-therapist bond influence therapists' assessment of termination risk? and (3) Can therapists who anticipate that their clients will leave therapy unfinished inadvertently increase the likelihood that their clients will terminate early?

Clients may be reticent to tell their therapists when they consider ending treatment, thus limiting therapists' ability to accurately assess the risk of premature termination. Most therapists in the study reported that their clients had left treatment without communicating their reasons for terminating. Clients had offered explanations for ending therapy in only a few cases; in only one case did a client do so before he stopped coming to sessions. This pattern fits with previous research on premature termination which indicates that clients are unlikely to communicate their reasons for 
leaving treatment when they are dissatisfied (Pekarik, 1983). Unfortunately, this absence of direct feedback may leave therapists guessing.

Most therapists in the study described mixed feelings about their clients' early terminations. One therapist recalled that he had felt a combination of sadness for not being able to help his former client more, and confusion about why his client had left treatment. Another therapist explained that, in addition to feeling regret for the mistakes he had made in treatment, he had felt intense curiosity about what had happened to the client, and anxiety for her well-being. A third therapist said that her frustration and regret over the termination was tempered by her relief to see the client gone. These examples illustrate that therapists may experience complicated, and even conflicting, emotions in the wake of their clients' departures. A few therapists reported that they continued to feel the emotional impact of the termination months and years later. Given that therapists may suffer lasting personal impact when a client leaves treatment, it seems reasonable to speculate that experiences of premature termination can have a negative effect on therapists over the course of their careers, and be one contributor to therapist burnout (Pekarik, 1985).

In contrast to the personal impact of these terminations on the study participants, almost every therapist reported that having a client terminate prematurely had not affected his or her own sense of professional competence. Most attributed this lack of professional impact to their years of clinical experience, a finding that is not surprising in light of the fact that all the participants are board certified psychologists with extensive experience and knowledge about the many challenges inherent in conducting psychotherapy. Although a few therapists did report that the termination had affected 
their confidence, all therapists in the study viewed their former clients as being responsible for the termination. Although it understandable that therapists may defend against thoughts of self-blame when analyzing premature terminations, perhaps benefits can be derived from greater personal scrutiny in which they honestly appraise, possibly with the assistance of peer consultation, what role they may have played in causing the client to leave therapy early.

\section{F. Professional Development}

Although they may not have previously engaged in intensive scrutiny of possible mistakes, in the process of participating in the study therapists were willing to look back on their work with the benefit of hindsight, and note ways that they would have approached treatment differently. Admittedly, they differed considerably on how they would have changed their strategies. Opinions varied regarding whether focusing treatment on relieving symptoms, facilitating insight, or providing empathy would have led to a more favorable outcome. Some therapists felt that their interventions were sound, and that no adjustments would have changed the outcome, while others felt that switching the order of their interventions would have made a difference. Therapists typically discussed changes that might have resolved the particular problems in treatment which they had already identified. For example, one therapist said that he could have kept his client in treatment had he focused more on reducing his client's addiction problems which ultimately interfered with treatment; also, he regretted his choice to bring the client's family into therapy sessions because that change in the structure of treatment seemed to disrupt his relationship with the client. Yet, as discussed earlier, clients may have varying reasons for departing therapy prematurely, and many may never 
share their perspective with their therapists. Once again, the fact that therapists may not know the whole story about what went wrong may limit their ability to form conclusions about how to avoid premature terminations in the future.

Although most study therapists derived valuable lessons from their experiences, they remained uncertain about how to prevent future premature terminations. Some participants warned that therapists should be prepared to work with particularly difficult clients. Others concluded that the maintenance of a strong therapeutic relationship is essential to achieving success. Still others suggested that therapists should seek regular consultation and supervision, and strive to learn about their own strengths and weaknesses. One therapist concluded that her cautiousness with clients, and her interest in their stories, can weaken her ability to offer them containment when they disclose too much, too early in treatment. Although this therapist knew that she needed to learn to contain her clients' disclosure, she ultimately felt uncertain that she would be able to limit their revelations without communicating some degree of rejection. Like most therapists in the study, she remained uncertain about how to avoid repeating the problem in the future even though she felt that she understood what had gone wrong.

\section{G. $\underline{\text { Limitations }}$}

A few limitations warrant attention before discussing the implications of the study's findings for psychotherapy practice and research. First, the findings apply to the small sample of therapists who participated in the study, and may or may not be relevant to the larger populations of board certified therapists, or experienced therapists in general. Similarly, the study sample was almost entirely comprised of therapists working in private practice, and therefore would not speak to issues common in other treatment 
formats that could affect the risk of premature termination (i.e., socio-economic problems in some clinical populations.) That said, the sample itself was diverse with regard to the gender of the therapists (four women, seven men), although all participating therapists were clinically experienced, board certified, and Caucasian. In assessing the value of the study findings, it is important to bear in mind that qualitative research is best evaluated in terms of the degree to which the study finding accurately represent the sample of participants, are coherent, and have practical applicability (Hill, Thompson, \& Williams, 1997). As is evident in the results, some of the study findings were common within the sample, and central themes did emerge from the data that form a coherent picture of the phenomenon of premature termination.

Second, the study findings were drawn from the participating therapists' selfreport, and trustworthy only to the extent that the participants' recollections were accurate, honest, and insightful. Moreover, participating therapists were asked to discuss the sensitive topic of a "failed" case. In spite of this limitation on the findings, therapists in the study shared generously, recalling their experiences with candor and detail. The therapists frequently acknowledged their own role in the premature terminations, as well as the personal impact that the terminations had on them, suggesting that they offered trustworthy self-reports.

Third, as with any study, the study findings are inherently colored by the expectations and the biases of the research team. On the other hand, one benefit of the $\mathrm{CQR}$ methodology is that it provides guidelines for identifying and managing bias in the research process. Thus, the research team worked continually to remain aware of, and mitigate the effects of, their biases by: (1) recording and discussing their biases and 
expectations before encountering the data, (2) setting ground rules for group work to avoid potentially biasing group processes, and (3) striving for quality debate and group consensus on how to code the data. The findings align with many of the common expectations held by research team members; for example, team members anticipated that therapists would experience a sense of failure after their clients left, that their sense of competence would be unaffected, that they would identify a variety of missteps, and that therapists would conclude that they should work toward forming better relationships with their clients in the future. Given that the research team reached many of the results which they had expected, The research team was confident that their findings were trustworthy, and not the result of researcher bias, because of the rigor of the research method employed, and the team's attention to their own biases.

\section{H. Implications for Research}

As is common to many qualitative research endeavors, the study offers few answers, but provides many questions for future research. For example, the findings indicate that problems in therapy such as a lack of progress, client resistance or dissatisfaction, therapist mistakes or frustration, disagreements between client and therapist, and disruptions in the emotional bond can give rise to one another, and come together to precipitate premature termination. Perhaps other researchers can explore whether problems in therapy that precede premature termination follow identifiable patterns, and whether therapists can reduce the likelihood of premature termination if armed with such knowledge. Similarly, researchers can examine the occurrence and impact of therapist mistakes, and compare different approaches to repairing the damage that may follow. Future research may also explore how therapists can best respond 
following premature termination. For example, researchers can assess the degree to which premature terminations affect therapists' emotional well-being and risk of burnout. Also, researchers can seek to identify best-practices regarding professional development following a premature termination.

This study also speaks to methodological issues in psychotherapy research. The findings demonstrate that the methodological challenges created by the interpersonal and subjective nature of psychotherapy may be better conceptualized in terms of concepts which capture these dynamics, such as the therapeutic alliance. In addition, this study offers yet another example of the practical value of qualitative research. Qualitative methods such as $\mathrm{CQR}$ offer researchers a rigorous means of collecting rich data, particularly when exploring internal processes such as personal reactions and growth following a significant experience.

\section{Implications for Practice}

The findings of this study carry implications for the practice of psychotherapy as well. First, therapists can assess their clients' risk of leaving treatment prematurely by attending to problems in the therapeutic relationship. Therapists can strive to discern such problems in the therapeutic relationship by observing both their own degree of agreement with clients about the means and ends of treatment, and the quality of their emotional bonds with clients. Disruptions in the therapeutic relationship may be natural, but if left unresolved can undermine the process of treatment and increase the risk that clients will leave therapy early. Thus, therapists can strengthen their practice by employing techniques intended to maintain the therapeutic relationship, and to recognize and mend alliance ruptures (Safran \& Muran, 2000). 
Second, therapists sometimes inadvertently contribute to the risk of premature termination through their own mistakes or personal reactions to treatment. Presumably, all therapists strive to avoid making mistakes of consequence, but the fallibility of human nature suggests that clinicians will occasionally trip up. Accepting that mistakes will occur, therapists will benefit from attempts to: (1) establish strong therapeutic bonds from the outset of treatment, (2) understand the situations in which a mistake is most damaging to the therapeutic relationship and take extra caution when those situations arise, and (3) take corrective action as soon as a mistake has been made. Even before a mistake occurs, a therapist who from the outset of treatment has invested effort in the establishment of a strong bond with a client will more likely be forgiven for his or her error. Being alert to precarious times or circumstances in the course of therapy is also important, such as during times when a client is especially vulnerable, or during times when the therapist is under personal stress. Lastly, once the error is made, the therapist needs to find a way to repair the hurt before the therapy is completely undermined.

Third, therapists may experience complicated and enduring reactions when a client leaves treatment. They may face a host of emotions such as sadness, anger, confusion, remorse, frustration, and even occasional relief in response to a client's premature departure. Moreover, therapists may find that, in addition to continuing to think about a former client, their emotional reactions may linger for months or years after a case has ended. Ultimately, such troubling experiences may contribute to therapists' professional fatigue, and may reduce their ability to be emotionally available for future clients. In order to continue providing the best quality treatment, therapists need to 
recharge their emotional batteries periodically by engaging in activities such as peer supervision.

Lastly, the findings of this study demonstrate that therapists can learn a great deal about their clients and themselves from cases of premature termination; however, therapists may find that several tendencies, evident in the study findings, detract from their motivation to question their work, and engage in professional development following a premature termination: (1) Therapists may find that attributing the termination to the client's psychopathology is the easiest and most expedient explanation; (2) A therapist's sense of professional competence may be largely unaffected by the termination, especially if the therapist has been practicing for many years; and (3) A therapist who attempts to understand why a client left treatment prematurely will likely be confronted by the limits of his or her perspective on what is fundamentally a dynamic and interpersonal process. 


\section{APPENDIX A}

\section{SEMI-STRUCTURED INTERVIEW}

What Went Wrong? Therapists' Reflections on their Role in a Premature Termination

In this interview, I will ask you to discuss your experience with a former client who withdrew from treatment prematurely. I will ask you to reflect on this case, and to describe your thoughts and actions, both then and now. I am interested in your reflections on your own actions and inner dialogue rather than the psychopathology of the client. Your responses to the following questions are confidential and voluntary, and you may skip any question if you choose to.

Please recall a client who, having attended therapy for at least four sessions, left therapy before you felt that treatment was complete. We will be discussing the case of a client whose departure from therapy was not due to a geographical move or a change in his or her ability to pay for therapy. I will not ask you to provide information that could identify this client.

Why did this client seek your help initially?

How long did you see this client in therapy?

What progress, if any, did the client make in therapy?

What indication did you have that the client might leave therapy?

What did you do to avert early termination?

How did the client respond to your efforts?

How did the client end treatment with you?

What was your understanding, at the time, of why this client left treatment early?

How did you feel when this client left therapy?

How did the departure of this client affect your sense of competence as a therapist?

What characteristics of this client contributed to her/his premature departure from treatment?

What missteps, if any, do you feel that you made in your work with this client?

In what way might your actions have contributed to the client's early departure from therapy? 
Since the time of that termination, how have your thoughts about this termination changed?

What questions linger in your mind regarding this case?

How has your experience with this client affected your work with subsequent clients?

Knowing what you know now, what would you do differently if you were treating this client again?

Given your experience with this client, what advice would you offer to a beginning therapist faced with a client who may leave therapy early? 


\title{
APPENDIX B
}

\section{CONSENT TO PARTICIPATE IN RESEARCH}

\author{
What Went Wrong? Therapists' Reflections on their Role in a Failed Alliance
}

\section{The Research Study}

You are invited to participate in the above named research study. Alessandro Piselli, a graduate student in Clinical Psychology at the University of Massachusetts Amherst, is the principal investigator of this study. Mr. Piselli is conducting this study as a Master's Thesis project under the supervision of Professor Richard Halgin, Ph.D..

\section{Purpose of the Study}

This study explores how therapists understand, and learn from, cases in which a former client terminated therapy prematurely due to strains in the therapeutic alliance.

\section{Your Participation}

Your participation in this study is voluntary, and you may withdraw at any time. You may likewise refuse to answer any question during the course of your participation.

If you choose to participate, you will take part in a one-hour interview conducted by the principal investigator. You will be asked to reflect on and discuss your thoughts and actions regarding a case in which a former client left treatment prematurely. You will be asked to describe the relationship that you formed with this client, as well as problems that arose in that relationship. This study will focus on the experiences of 10 therapists. The investigator intends for the results of this study to reflect commonalities in the descriptions offered by the participating therapists.

No further participation will be required of you following the one-hour interview. The investigator may wish to contact you to ask brief follow-up questions if clarification is needed.

\section{Potential Risks and Benefits}

Given that this study focuses on treatments that were ultimately unsuccessful, you will be asked to speak about your regrets regarding this case, as well as personal and professional factors that may have contributed to the termination. You may find some questions difficult to answer, but you are encouraged to answer as openly and honestly as you are willing.

You may find that, by reflecting on these past experiences, you gain some new perspective on your previous work. You are encouraged to share such insights with the investigator. Such insights may prove valuable to other therapists who are confronted with a challenging therapeutic relationship. 


\section{Audio-taping and Confidentiality}

Your interview with the investigator will be audio-taped. This audio file will be transcribed verbatim. Although quotes and summaries of your words will appear in resulting publications, the confidentiality of your identity, and your former client's identity, will be maintained. Your name and contact information will be kept in a protected location, separate from data collected during the study. Any identifying information about you, or your former client, will be deleted. The investigator will ask you to provide an appropriate pseudonym for your former client. Full transcripts of this interview will be seen by the investigator, a team of trained research assistants, and Richard Halgin, Ph.D.. Please share any concerns that you may have regarding your confidentiality. If necessary, appropriate measures will be taken to further maintain your confidentiality.

I have read this consent to participate in research. I have been given an opportunity to ask questions, and to address concerns. I understand the nature of this study, and what my participation involves. I am willing to participate in this research study. 


\section{APPENDIX C}

\section{STUDY DEBRIEFING FORM}

What Went Wrong? Therapists' Reflections on their Role in a Failed Alliance

This study poses the question, how do therapists understand, and learn from, cases in which a former client terminated therapy prematurely due to strains in the therapeutic alliance? I have chosen this question in particular for its relevance to both psychotherapy practice and research.

Rather than testing an existing hypothesis, this study aimed generate new hypotheses about how problems in the therapeutic alliance contribute to the risk of premature termination. For that reason, I chose to conduct interviews with expert therapists. The comments that you shared during our interview will be culled along with those of the nine other contributing therapists. I suspect that the participating therapists will share some central insights regarding the question posed in this study. Thank you for your willingness to contribute your experience and knowledge to this endeavor.

Please let me know if you would like to receive a summary of this study's findings when it is completed. You can reach me at the e-mail address given below.

Again, thank you for your time and your contribution.

Sincerely,

Sandro Piselli

Principal Investigator

apiselli@psych.umass.edu

Should you have further questions or concerns regarding this study, please feel free to contact the research advisor (Richard Halgin, rhalgin@ psych.umass.edu) or the Chair of the Psychology Department (Melinda Nozak, mnovak@psych.umass.edu). You may also direct questions concerning your rights as a research subject to the University of Massachusetts Amherst Human Research Protection Office (HRPO) at (413) 545-3428 or humansubjects@ ora.umass.edu. 


\section{REFERENCES}

Arnow, B. A., Blasey, C., Manber, R., Constantino, M. J., Markowitz, J. C., Klein, D. N., et al. (2007). Dropouts versus completers among chronically depressed outpatients. Journal of Affective Disorders, 97(1), 197-202.

Barrett, M. S., Chua, W.-J., Crits-Christoph, P., Gibbons, M. B., \& Thompson, D. (2008). Early withdrawal from mental health treatment: Implications for psychotherapy practice. Psychotherapy: Theory, Research, Practice, Training, 45(2), 247-267.

Bordin, E. S. (1979). The generalizability of the psychoanalytic concept of the working alliance. Psychotherapy: Theory, Research \& Practice, 16(3), 252-260.

Connell, J., Grant, S., \& Mullin, T. (2006). Client initiated termination of therapy at NHS primary care counselling services. Counselling \& Psychotherapy Research, 6(1), 60-67.

Corning, A. F., \& Malofeeva, E. V. (2004). The Application of Survival Analysis to the Study of Psychotherapy Termination. Journal of Counseling Psychology, 51(3), 354-367.

Derisley, J., \& Reynolds, S. (2000). The transtheoretical stages of change as a predictor of premature termination, attendance and alliance in psychotherapy. British Journal of Clinical Psychology, 39(4), 371-382.

Farber, B. A. (1983). Psychotherapists' perceptions of stressful patient behavior. Professional Psychology: Research and Practice, 14(5), 697-705.

Fleischer, J., \& Wissler, A. (1985). The therapist as patient: Special problems and considerations. Psychotherapy: Theory, Research, Practice, Training, 22(3), 587594.

Frayn, D. H. (1992). Assessment factors associated with premature psychotherapy termination. American Journal of Psychotherapy, 46(2), 250-261.

Frayn, D. H. (2008). Premature Termination Issues Involving Psychoanalytic Therapy. In W. T. O'Donohue \& M. A. Cucciare (Eds.), Terminating Psychotherapy: A Clinician's Guide (pp. 33-52). New York, NY, US: Routledge: Taylor \& Francis Group.

Gelso, C., \& Carter, J. (1994). Components of the psychotherapy relationship: Their interaction and unfolding during treatment. Journal of Counseling Psychology, 41(3), 296-306.

Goldfried, M. R., \& Pachankis, J. E. (2007). On the next generation of process research. Clinical Psychology Review, 27(6), 760-768.

Guy, J. D. (1987). The personal life of the psychotherapist. New York: Wiley. 
Guy, J. D., Poelstra, P. L., \& Stark, M. J. (1989). Personal distress and therapeutic effectiveness: National survey of psychologists practicing psychotherapy. Professional Psychology: Research and Practice, 20(1), 48-50.

Guy, J. D. (2000). Holding the holding environment together: Self-psychology and psychotherapist care. Professional Psychology: Research and Practice, 31(3), 351-352.

Hill, C. E., Knox, S., Thompson, B. J., Williams, E. N., Hess, S. A., \& Ladany, N. (2005). Consensual Qualitative Research: An Update. Journal of Counseling Psychology, 52(2), 196-205.

Hill, C. E., Thompson, B. J., \& Williams, E. N. (1997). A guide to conducting consensual qualitative research. Counseling Psychologist, 25(4), 517-572.

Hilsenroth, M. J., Handler, L., Toman, K. M., \& Padawer, J. R. (1995). Rorschach and MMPI-2 indices of early psychotherapy termination. Journal of Consulting and Clinical Psychology, 63(6), 956-965.

Kessler, R., Chiu, W., Demler, O., \& Walters, E. (2005). Prevalence, Severity, and Comorbidity of 12-Month DSM-IV Disorders in the National Comorbidity Survey Replication. Archives of General Psychiatry, 62(6), 617-627.

Kimerling, R., Zeiss, A., \& Zeiss, R. (2000). Therapist emotional responses to patients: Building a learning-based language. Cognitive and Behavioral Practice, 7(3), 312321.

Kivlighan, D. M., Jr., \& Shaughnessy, P. (2000). Patterns of working alliance development: A typology of client's working alliance ratings. Journal of Counseling Psychology, 47(3), 362-371.

Mahon, J. (2000). Dropping out from psychological treatment for eating disorders: What are the issues? European Eating Disorders Review, 8(3), 198-216.

Maramba, G. G., \& Nagayama Hall, G. C. (2002). Meta-analyses of ethnic match as a predictor of dropout, utilization, and level of functioning. Cultural Diversity and Ethnic Minority Psychology, 8(3), 290-297.

Meissner, W. W. (1996). The therapeutic alliance. New Haven, CT, US: Yale University Press.

Meissner, W. W. (2006). The Therapeutic Alliance--A Proteus in Disguise. Psychotherapy: Theory, Research, Practice, Training, 43(3), 264-270.

Miller, L. (1998). Our own medicine: Traumatized psychotherapists and the stresses of doing therapy. Psychotherapy: Theory, Research, Practice, Training, 35(2), 137146. 
Norcross, J. C., Guy, J. D., Dryden, W., \& Spurling, L. (1989). Ten therapists: The process of becoming and being. In On becoming a psychotherapist. (pp. 215-239). New York, NY, US: Tavistock/Routledge.

Norcross, J. (2000). Psychotherapist self-care: Practitioner-tested, research-informed strategies. Psychology: Research and Practice, 31, 710-713.

Norcross, J. (2005). A primer on psychotherapy integration. In J. Norcross \& M.R. Goldfried (Eds.), Handbook of psychotherapy integration (2nd ed.). New York: Oxford University Press.

Ogrodniczuk, J. S., Joyce, A. S., \& Piper, W. E. (2005). Strategies for Reducing PatientInitiated Premature Termination of Psychotherapy. Harvard Review of Psychiatry, 13(2), 57-70.

Pekarik, G. (1983). Improvement in clients who have given different reasons for dropping out of treatment. Journal of Clinical Psychology, 39(6), 909-913.

Pekarik, G. (1985). Coping with dropouts. Professional Psychology: Research and Practice, 16(1), 114-123.

Pekarik, G. (1992). Relationship of clients' reasons for dropping out of treatment to outcome and satisfaction. Journal of Clinical Psychology, 48(1), 91-98.

Piper, W. E., Ogrodniczuk, J. S., Joyce, A. S., McCallum, M., Rosie, J. S., O'Kelly, J. G., et al. (1999). Prediction of dropping out in time-limited, interpretive individual psychotherapy. Psychotherapy: Theory, Research, Practice, Training, 36(2), 114122.

Reis, B. F., \& Brown, L. G. (1999). Reducing psychotherapy dropouts: Maximizing perspective convergence in the psychotherapy dyad. Psychotherapy: Theory, Research, Practice, Training, 36(2), 123-136.

Reilly, C. (2000). 'The role of emotion in cognitive therapy, cognitive therapists, and supervision': Response. Cognitive and Behavioral Practice, 7(3), 343-345.

Safran, J. D., \& Muran, J. C. (1996). The resolution of ruptures in the therapeutic alliance. Journal of Consulting and Clinical Psychology, 64(3), 447-458.

Safran, J. D., \& Muran, J. C. (2000). Negotiating the therapeutic alliance: A relational treatment guide. New York, NY, US: Guilford Press.

Samstag, L. W., Batchelder, S. T., Muran, J. C., Safran, J. D., \& Winston, A. (1998). Early identification of treatment failures in short-term psychotherapy: An assessment of therapeutic alliance and interpersonal behavior. Journal of Psychotherapy Practice \& Research, 7(2), 126-143. 
Todd, D. M., Deane, F. P., \& Bragdon, R. A. (2003). Client and therapist reasons for termination: A conceptualization and preliminary validation. Journal of Clinical Psychology, 59(1), 133-147.

Tryon, G. S., \& Kane, A. S. (1990). The helping alliance and premature termination. Counselling Psychology Quarterly, 3(3), 233-238.

Tryon, G. S., \& Kane, A. S. (1993). Relationship of working alliance to mutual and unilateral termination. Journal of Counseling Psychology, 40(1), 33-36.

Wierzbicki, M., \& Pekarik, G. (1993). A meta-analysis of psychotherapy dropout. Professional Psychology: Research and Practice, 24(2), 190-195. 